A PRELIMINARY COST AND

ENGINEERING ESTIMATE FOR

DESALINATING PRODUCED

FORMATION WATER ASSOCIATED

WITH CARBON DIOXIDE CAPTURE AND STORAGE

W. L. Bourcier, T. J. Wolery, T. Wolfe, C. Haussmann, T. A. Buscheck, R. D. Aines

June 29, 2011

International Journal of Greenhouse Gas Control 
This document was prepared as an account of work sponsored by an agency of the United States government. Neither the United States government nor Lawrence Livermore National Security, LLC, nor any of their employees makes any warranty, expressed or implied, or assumes any legal liability or responsibility for the accuracy, completeness, or usefulness of any information, apparatus, product, or process disclosed, or represents that its use would not infringe privately owned rights. Reference herein to any specific commercial product, process, or service by trade name, trademark, manufacturer, or otherwise does not necessarily constitute or imply its endorsement, recommendation, or favoring by the United States government or Lawrence Livermore National Security, LLC. The views and opinions of authors expressed herein do not necessarily state or reflect those of the United States government or Lawrence Livermore National Security, LLC, and shall not be used for advertising or product endorsement purposes. 


\title{
A Preliminary Cost and Engineering Estimate for Desalinating Produced Formation Water Associated With Carbon Dioxide Capture and Storage
}

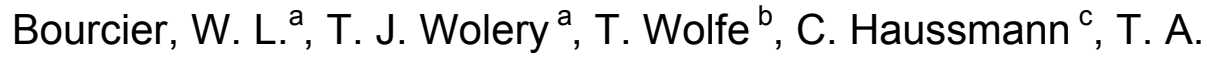 \\ Buscheck $^{a}$, and R. D. Aines ${ }^{a}$
}

a - Lawrence Livermore National Laboratory, 7000 East Avenue, Livermore CA 94550

b - PerLorica Inc., P.O. Box 190, Rough and Ready, California 95975

c - Water Systems Specialists, Inc., 5808 Princeton Ave NE, Seattle, WA 98105

Corresponding author:

William Bourcier

L-184

Lawrence Livermore National Laboratory

Livermore, California 94550

925-422-9885 office

925-667-7165 cell

bourcier1@IInl.gov 


\begin{abstract}
The risk associated with storage of carbon dioxide in the subsurface can be reduced by removal of a comparable volume of existing brines (e.g., Buscheck et al., 2011). In order to avoid high costs for disposal, the brines should be processed into useful forms such as fresh and low-hardness water. We have carried out a cost analysis of treatment of typical subsurface saline waters found in sedimentary basins, compared with conventional seawater desalination. We have also accounted for some cost savings by utilization of potential well-head pressures at brine production wells, which may be present in some fields due to $\mathrm{CO}_{2}$ injection, to drive desalination using reverse osmosis. Predicted desalination costs for brines having salinities equal to seawater are about half the cost of conventional seawater desalination when we assume the energy can be obtained from excess pressure at the well head. These costs range from 32 to $40 \phi$ per cubic meter permeate produced. Without well-head energy recovery, the costs are from 60 to $80 \phi$ per cubic meter permeate. These costs do not include the cost of any brine production or brine reinjection wells, or pipelines to the well field, or other sitedependent factors.
\end{abstract}

Keywords: carbon capture and storage, desalination, brines, reverse osmosis, osmotic pressure, produced waters 


\subsection{Introduction}

A major risk associated with geologic sequestration of carbon dioxide is the buildup of pressure in the subsurface due to injection. The maximum sustainable pressure is limited by the ability of the cap-rock to contain the $\mathrm{CO}_{2}$ as a low permeability barrier, and also the potential for the overpressure to create new fractures, or to reactivate existing fractures, which would then open new flow paths for $\mathrm{CO}_{2}$ escape (Rutqvist et al., 2007). Moreover, emplacement of $\mathrm{CO}_{2}$ could drive the existing brine into useful aquifers where potable water would be contaminated, and could also increase the likelihood of induced seismicity (Bachu, 2008).

A method to avoid these potential problems is to withdraw the saline fluid existing in the subsurface and thus reduce the amount of overpressure. However, the outstanding problem with this approach is the disposition of the withdrawn fluids. Because of their high salinities (>10,000 mg/L TDS), these fluids are generally not useful for either domestic or agricultural use. The large volume of $\mathrm{CO}_{2}$ to be emplaced implies a similarly large fluid volume must be produced. Such a large volume of brine cannot be disposed of as-is without significant cost.

Desalinating the produced brines using membrane-based technologies is a potential solution that would allow brine withdrawal, with disposal partly accounted for by production of useful low salinity water. Moreover, some of the energy needed to drive desalination could be obtained directly from the overpressure present in the subsurface generated by the emplacement of $\mathrm{CO}_{2}$ for some sequestration sites. This would allow a re-capture of some fraction of the energy used to pressurize and inject $\mathrm{CO}_{2}$ into the subsurface to be used to desalinate the produced fluids. This can be done directly using reverse osmosis (RO), a technology that uses a pressure gradient across a semipermeable membrane to produce desalinated water.

An additional benefit is that strategic withdrawal and reinjection of brines may allow manipulation of the location and migration of the $\mathrm{CO}_{2}$ pool in the subsurface. This could be accomplished by using brine injection/withdrawal to alter the subsurface pressure field so as to affect the pressure gradient surrounding the $\mathrm{CO}_{2}$ pool in the desired way. This ability to manipulate the $\mathrm{CO}_{2}$ by imposing pressure gradients has the potential to substantially reduce the inherent risk of geologic sequestration of $\mathrm{CO}_{2}$ (Buscheck et al., 2010).

The permeate (low salinity water) produced from the reverse osmosis desalination process would be suitable for power plant cooling, or could be used for agricultural, domestic, or other uses for which it has monetary value. The residual brine produced by the process could be re-injected back into the aquifer, such that there would be 
minimal brine disposal cost. With brine re-injection, the net volume of water removed would be approximately equal to the amount of fresh water recovered in the reverse osmosis process.

In this paper, we examine the costs and benefits associated with the concept of removal and desalination of fluids present in $\mathrm{CO}_{2}$ sequestration sites. We note that the full development of all of the concepts noted in this paper will require a considerable body of future work. The scope of this paper is necessarily limited to only one aspect, water treatment. Using brine removal to control reservoir pressure and manage plume shape and migration is being developed within the concept of Active $\mathrm{CO}_{2}$ Reservoir Management, or ACRM (Buscheck et al., 2011; Court et al., 2011). The need to manage displaced brine has been noted in the case of commercial scale sequestration in the Rock Springs Uplift of Wyoming (Surdam et al., 2011). Court et al. (2011) note other examples where this need has been realized. We note that the issue of pressure buildup in saline formations targeted for $\mathrm{CO}_{2}$ sequestration has become a somewhat controversial topic (cf. Ehlig-Economides and Economides, 2010; Dooley and Davidson, 2010), and that more and specific analyses will be required to determine where pressure buildup (or brine migration, which relieves pressure buildup) might and might not be a potential problem and under which conditions it may be possible to produce pressurized brine.

\subsubsection{Desalination Technologies}

For most of human history, desalination of water has been accomplished through distillation. Most of the world's desalination of ocean water is still carried out using thermal distillation (Buros, 2000). However, membrane-based methods such as reverse osmosis, developed over the last 50 years, are now the technology of choice for new desalination plants (NRC, 2008). Membrane-based methods are expected to soon overtake thermal methods in total capacity, driven mainly by the high energy costs of thermal methods (Karagiannis and Soldatos, 2008). The heat of vaporization of water is so large $\left(\sim 630 \mathrm{~kW}-\mathrm{h} / \mathrm{m}^{3}\right)$ that even extremely efficient energy recovery $(>90 \%)$ in thermal systems cannot compete with energy costs of $4-6 \mathrm{~kW}-\mathrm{h} / \mathrm{m}^{3}$ typical for seawater RO systems (Khawaji et al., 2008).

Reverse osmosis $(\mathrm{RO})$ uses a membrane permeable to water but impermeable to salt to separate salt from water. To carry out reverse osmosis, a pressure gradient is imposed across a membrane that separates the solution to be de-salted (e.g. ocean water) from a more dilute solution. Because of the osmotic pressure gradient, water naturally tends to flow from the dilute solution to the salt solution. By applying a pressure larger than the osmotic pressure in an opposite direction, water can be forced to flow from the salt solution across the membrane to the dilute side. For desalination of seawater, pressures on the order of 5-7 MPa (700-1200 psi) are used to overcome the 
2.5 $\mathrm{MPa}$ ( $\sim 360 \mathrm{psi})$ of osmotic pressure gradient between ocean water and dilute permeate (Fritzmann et al., 2007).

Typical aromatic polyamide thin film composite reverse osmosis membranes are composed of a $200 \mathrm{~nm}$ layer of semi-permeable polyamide that is cast onto a porous polysulfone support material (Figure 1) which itself sits on a spacer to allow water flow along the membrane. [FIGURE 1] The pore size of the polyamide is controlled for the specific application of use. Pores size estimates are in the range of 5-10 Angstroms (Baker, 2004). Smaller pore-sized (tighter) membranes are used for high salinity solutions such as seawater in order to increase salt rejection. Larger pore-size membranes are used for more dilute (brackish) waters where less salt rejection is needed to produce permeates that are potable $(<500 \mathrm{mg} / \mathrm{L}$ TDS). Salt rejection for tight membranes is greater than $99 \%$; salt rejection for brackish water membranes is $98-99 \%$ (Amjad, 1993). The downside to high rejection is that the membrane is less permeable for water transport and therefore higher driving pressures are needed to produce the same water flux (Fritzmann et al., 2007).

Reverse osmosis is limited by the maximum pressure difference that the membrane spacers can withstand without collapsing and causing the membrane to become impermeable to water flow (Matsuura, 2001). The current limit for commercially available membranes is about $8.3 \mathrm{MPa}(1200 \mathrm{psi})$. The semi-permeable polyamide layer can withstand higher pressures and does not itself currently limit maximum $R O$ pressures.

Nanofiltration (NF) membranes are similar to RO membranes, but are synthesized with larger pores and usually bear some surface charge due to changes in the membrane chemistry. They are able to separate divalent from monovalent ions. For example, a nanofiltration membrane may allow $\mathrm{Na}$ and $\mathrm{Cl}$ to pass through the membrane freely, while rejecting greater than $90 \%$ of the sulfate and calcium in many fluids (Hilal, et al., 2004). The actual selectivity of NF membranes varies, with some functioning more like RO membrances with low rejection. NF membranes are typically used for removing hardness (divalent cations such as calcium) from waters, and also for removing sulfate to prevent sulfate mineral scaling. Because NF removes only some fraction of the electrolyte content, it operates at lower pressure differences than RO (because the osmotic pressure depends on the salinity gradient across the membrane, not the total salinity). NF can be used in front of RO to partially reduce the feed salinity, and reduce pressure for the subsequent RO stage. In this way, the maximum salinity limit for membrane treatment can be increased.

Reverse osmosis systems can operate over a range of water recoveries. Recovery is defined as the volume ratio of product water (permeate) to feed. High recoveries are preferred because they more efficiently use the energy applied to pressurize the fluid. 
Once feed water is pressurized, it can continue to generate a clean permeate until its salinity increases to the point where the osmotic pressure gradient is nearly equal to the applied pressure. Upon exiting an RO unit, the residual brine (on the feed side of the membrane) is still pressurized. Energy recovery methods are generally used to capture that energy, using either turbines, or pressure exchangers that transfer the pressure of the exiting concentrate to the upstream feed.

The downside to high recoveries is the increased likelihood of mineral scaling. High pressures cause more rapid water flux through the membrane and increases "concentration polarization" at the membrane surface. This refers to the buildup at the membrane surface of anything contained in the fluid that does not pass through the membrane, in particular salt and high MW species too large to fit through the 5-10 pores in the polyamide layer.

All of these considerations must be accounted for in accessing desalination costs. Software packages such as WTCOST (Moch, 2008) have been created that provide for unit process costs of each treatment step and are used to identify the minimum cost treatment configuration. Seawater desalination costs for membrane-based systems generally vary between $\$ 0.50$ and $\$ 1.00$ per cubic meter of product (Karagiannis and Soldatos, 2008). Costs increase with the salinity of the fluid because of the higher pressure needed to drive water through the membranes. Energy costs for seawater desalination are generally half the total cost. Because membranes are easily fouled by organics, biological activity, and mineral formation, pretreatment to avoid fouling is needed and can significantly increase cost. Pretreatment is highly specific to the feed, with waters having high organic productivity being particularly difficult to pretreat. Formation waters are generally not very biologically active and some of these pretreatment costs can therefore be avoided. However, formation waters may contain other components that would introduce a different set of pretreatment problems and costs. We will discuss this later in this paper.

\subsubsection{Limitations of Membrane Desalination Technologies}

The main limitation of membrane-based desalination technologies is the salinity of the feed. Higher salinity requires a higher pressure difference across the membrane in order to produce permeate. This pressure difference must be maintained below a certain limit to avoid loss of permeability due to membrane compaction. As noted previously, this limit is associated with the properties of the spacers. Figure 2 shows the relationships between osmotic pressure and water recovery (percent extraction) during treatment of waters having a range of starting salinities. [FIGURE 2] A recovery of $20 \%$ means that for each $1000 \mathrm{ml}$ of feed, $200 \mathrm{ml}$ of permeate and $800 \mathrm{ml}$ of brine are produced. Lines are drawn for recoveries of $0,10,20$, and $50 \%$. This plot illustrates the basic effect, which is driven mainly by salinity as represented by TDS (Total Dissolved 
Salts), commonly given in $\mathrm{mg} / \mathrm{L}$. All the waters here are taken to be in the "seawater" family (which extends in nature to about $350,000 \mathrm{mg} / \mathrm{L} \mathrm{TDS}$, greater than the range shown here). The ionic ratios correspond to those in seawater, the essential feature being that these brines are $\mathrm{NaCl}$-dominated. The results here are representative for many but not all subsurface brines (cf. Kharaka and Hanor, 2007). At least two other major types occur: $\mathrm{Na}-\mathrm{Ca}-\mathrm{Cl}$ brines and $\mathrm{Na}-\mathrm{Cl}-\mathrm{SO}_{4}$ brines, which occur in the Rocky Mountain Basins region. Somewhat different results should be expected for waters of these types (we will present below examples of calculations for specific brine chemistries).

Figure 2 can be used to estimate the maximum osmotic pressure for a fluid undergoing desalination at a given recovery (it will be more accurate for a fluid in the seawater family). For example, for a salinity of $78,000 \mathrm{mg} / \mathrm{L}$ (shown by the left vertical dotted line), the initial osmotic pressure is about $6.2 \mathrm{MP}$ (900 psi), and after recovering $20 \%$ of the fluid as permeate, the residual brine would have an osmotic pressure of $8.2 \mathrm{MPa}$ (1200 psi), the upper maximum for current RO membranes. Above this pressure the membrane product spacers collapse and the membrane elements can no longer pass permeate to the discharge tube (see Figure 1).

Note that this pressure limit is not a limit for the functional part of the membrane, only the materials currently used as supports. Higher pressure membranes useful up to 10.3 MPa (1500 psi) have been developed and allow brines up to about 80,000 TDS to be desalinated (e.g., Baker, 2004) but are not yet commercially available.

\subsection{Subsurface brines}

To estimate brine desalination costs, we need to know the characteristics of the fluids present in the subsurface at proposed carbon storage sites. Because a catalog of site data are not yet available, we use here a database for subsurface brines co-produced from oil and gas wells and compiled by the U.S. Geological Survey (Breit, 2002). This dataset covers the oil and gas-producing areas of the U.S. and has over 14,000 analyses. These data are relevant because these brines are typical of sedimentary basins that host petroleum reservoirs in permeable rocks, sites that are also targets for subsurface $\mathrm{CO}_{2}$ storage (Kharaka, 2007). Analysis of these data provides compositional information on the brines present in sedimentary basins, and their distribution with depth and geographic location. The U.S.G.S. database contains abundant data for most of the states west of the Mississippi River, but does not have good coverage for most of the eastern states. We note that other databases of produced waters exist, notably NATCARB (Carr et al., 2007).

Figure 3 shows the distribution of salinities from the U.S.G.S. database for fluids produced from depths greater than 3000 feet (about one kilometer). [FIGURE 3] The 
salinity range varies widely up to over $300,000 \mathrm{mg} / \mathrm{L}$ (30 wt \%) where salt mineral saturation begins to limit TDS. Over half of the brines have salinities less than 85,000 $\mathrm{mg} / \mathrm{L}$ TDS. Although there is some tendency for brines to become more concentrated with depth, there are many exceptions to this. For example in Wyoming, waters in the Nugget Formation with salinities of over $80,000 \mathrm{mg} / \mathrm{LTDS}$ overlie the Tensleep Formation, which has waters with salinities less than 25,000 mg/L TDS (cf. data for Sublette County, Wyoming, from Breit, 2002).

The concentration of calcium plus magnesium (hardness, calcium + magnesium, expressed as equivalent $\mathrm{mg} / \mathrm{L}$ calcium) in the database is shown in Figure 4. [FIGURE 4] Fluids with relatively high hardness are more susceptible to scale formation, but are also amenable to calcium and magnesium removal using nanofiltation. Fluids with hardness above about $10,000 \mathrm{mg} / \mathrm{L}$ are prime candidates for salinity reduction using an NF-RO process which effectively increases the salinity maximum for membrane desalination by first removing hardness (calcium, magnesium, and other divalent ions) prior to removal of the remaining salts. Over $20 \%$ of produced waters have hardness in this range based on the U.S.G.S. database.

Some produced brines have significant hydrocarbon contents, which will require complete removal as these compounds are known to irreversibly foul RO membranes (Fritzmann et al., 2007). This is one of the reasons many co-produced waters from fossil fuel production are not currently treated, but are instead re-injected into the subsurface, at significant cost. For this reason, fluids from $\mathrm{CO}_{2}$ sequestration sites that contain significant amounts of hydrocarbons will be more costly to desalinate. Additional research is needed in this area to address this problem. New treatment methods may be needed if existing ones prove insufficient or overly costly. Other pre-treatment needs may arise from the presence of other components, such as dissolved iron and silica. In the present paper, we make the assumption that such problems can be dealt with at reasonable cost, and focus instead on mineral precipitation involving major ions and the development of osmotic pressure resulting from extraction of water.

Both mineral scaling and osmotic pressure can limit how much fresh water can be recovered from a given brine. An example is shown in Figures 5 and 6 for reverse osmosis treatment of three solutions: seawater, and two saline waters from formations in Sublette County, Wyoming, a potential carbon storage site (cf. http://www.electricityforum.com/news/nov08/DOEtofundcarboncaptureproject.html). The compositions of the two saline formation waters were taken from Breit (2002). The first Wyoming brine, "Sublette \#3" (UNIQID 49003037), from the Nugget Formation, is very saline $\left(86,000 \mathrm{mg} / \mathrm{L}\right.$ TDS, $\left.29,000 \mathrm{Na}^{+}, 2650 \mathrm{Ca}^{++}, 2400 \mathrm{~K}^{+}, 1200 \mathrm{SO}^{--}, 415 \mathrm{HCO}_{3}^{-}\right)$. The second Wyoming brine, "Sublette \#2" (UNIQID49003313), is a high sulfate brine of lower total salinity $\left(24,500 \mathrm{mg} / \mathrm{L}\right.$ TDS, $7800 \mathrm{Na}^{+}, 200 \mathrm{Ca}^{++}, 100 \mathrm{Mg}^{++}, 14,600 \mathrm{SO}^{--}$, 
$1340 \mathrm{HCO}_{3}{ }^{-}$) from the Tensleep Formation, which underlies the Nugget Formation. [FIGURE 5] [FIGURE 6]. In Figure 5 we show predicted mineral scaling of seawater and the Sublette County brines during reverse osmosis treatment simulated using the EQ3/6 modeling software (Wolery and Jarek, 2003). For seawater, Figure 5a shows that as the water is concentrated during reverse osmosis, both calcite $\left(\mathrm{CaCO}_{3}\right)$ and anhydrite $\left(\mathrm{CaSO}_{4}\right)$ are predicted to precipitate. However, both phases can be controlled using anti-scalants and do not necessarily limit water recovery. Likewise for the Sublette County \#3 brine, calcite and anhydrite are predicted to precipitate (Figure 5b). For the high sulfate Sublette \#2 brine (Figure 5c), only anhydrite is predicted to precipitate even at recoveries of over $85 \%$. However, in all three cases, at very high recoveries, halite $(\mathrm{NaCl})$ and other phases such as glauberite $\left(\mathrm{Na}_{2} \mathrm{Ca}\left(\mathrm{SO}_{4}\right)_{2}\right)$, nahcolite $\left(\mathrm{NaHCO}_{3}\right)$, and thenardite $\left(\mathrm{Na}_{2} \mathrm{SO}_{4}\right)$ are predicted to precipitate in quantitites that provide a firm upper limit to recovery.

We calculate the osmotic pressure for the same feed solutions as they are concentrated in the reverse osmosis process. The pressures are shown by the red and blue lines in Figure 6. The blue line is calculated using a simple formula based on ideal mixing (the van't Hoff equation; Dow, 2009). The red line shows a more rigorous calculation using Pitzer's equations and is based on thermodynamic measurements of salt solutions and includes non-ideal mixing corrections (Greenberg and Moller, 1989; Pabalan and Pitzer, 1987). As can be seen, at high salinities, the two methods differ by several MPa, indicating that the more rigorous osmotic pressure calculation must be used for solutions for modeling salinities above about 1 molal. Comparing Figure $6 \mathrm{~b}$ and $6 \mathrm{c}$ shows that the more rigorous calculated pressure can be either higher or lower than the van't Hoff value depending on the solution composition, and in particular on the relative amounts of monovalent and divalent ions.

The upper limit on recovery occurs when the lines cross the horizontal line drawn at 8.3 $\mathrm{MPa}(1200 \mathrm{psi})$, the current membrane technology pressure limit. For seawater (a), the absolute limit is a recovery of about $65 \%$, which corresponds to a practical recovery limit of less than about $50 \%$. This is because for normal operation, the pressure across the membrane must be equal to the osmotic pressure plus an additional differential pressure of $0.7-1.4 \mathrm{MPa}$ (100-200 psi) to maintain appreciable flow of water across the membrane. For the more saline Sublette \#3 water $(\sim 86,000 \mathrm{mg} / \mathrm{L}$ TDS) the theoretical recovery is limited by osmotic pressure to about $7 \%$, or for practical purposes, the brine is at the edge of treatability using conventional reverse osmosis. For the less saline Sublette \#2 water, recoveries of $80 \%$ appear achievable. Overall, it is apparent that the development of osmotic pressure is more limiting than mineral precipitation. 
We conclude that the potential for freshwater extraction from saline brines can be categorized as follows:

- 10,000-40,000 mg/L TDS: Standard RO with $\geq 50 \%$ recovery

- 40,000-85,000 mg/L TDS: Standard RO with $\geq 10 \%$ recovery; higher recovery possible using 10.3 MPa (1500 psi) RO membranes and/or multi-stage incremental desalination including NF (nanofiltration)

- 85,000-300,000 mg/L TDS: Multi-stage process (NF + RO) using process design that may differ significantly from seawater systems

- > 300,000 mg/L TDS brines: Not likely to be treatable

As can be seen in Figures 3 and 4, brines in the 10,000-85,000 mg/L TDS range appear to be abundant (geographically and with depth) and could be targeted in siting CCS operations. These brines will be chemically different than seawater and these differences will affect treatment costs. Brines greater in salinity than 85,000 will be expensive to treat and will not be addressed further in this paper.

\subsubsection{Desalination of seawater vs. saline formation water}

Because many of the candidate brines present in the subsurface at sequestration sites have salinities somewhat similar to that of seawater, we will use for our first cost analysis a generic fluid having a total salinity equal to that of normal seawater, but with specific chemical characteristics more typical of subsurface brines. This allows the most accurate cost estimate to be made with minimal additional assumptions. There is abundant experience and cost data available for the reverse osmosis desalination of seawater (Karagiannis and Soldatos, 2008).

A conventional seawater $\mathrm{RO}$ desalination system uses raw ocean water as feed. The ocean water is first filtered for particulates and micro-organisms. Instead of open water intakes, many treatment plants now take the feed from wells drilled into the coastal sand wedge to take advantage of the sand as a first filtration step (Frenkel, 2011). The water may then be acidified, have antiscalants added, filtered again at a finer size, and then pressurized and passed into the RO elements. The RO elements are arranged in multiple stages to maximize permeate recovery and minimize the energy used to pressurize the system. The feed water stays pressurized throughout the desalination process. It exits with a pressure only $1-30 \mathrm{kPa}$ lower than the starting pressure. The permeate fluid may be adjusted in $\mathrm{pH}$ and chlorinated prior to being sent to storage and distribution. The concentrate is sent to disposal, typically piped out to sea.

The major steps in desalination of saline formation water are compared with those of conventional seawater RO in Figure 7. [FIGURE 7] For the saline water, we assume for this analysis that we have a well-head pressure of $8.3 \mathrm{MPa}(1200 \mathrm{psi})$. This is at the 
upper limit of what can be used in current RO systems and therefore provides an endmember cost comparison. We also account for the likely differences for desalinating fluids pumped from the subsurface versus those obtained from the ocean. We then compare the process steps for seawater vs. pressurized brine and examine how they differ.

The first difference is that the saline formation fluids are assumed to be saturated with several mineral phases, a good assumption since they have had significant time in the subsurface to equilibrate with the surrounding reservoir rocks. These minerals include carbonates, sulfates, and silicates. As a consequence we include in our process costs much more extensive pre-treatment, in particular the addition of antiscalants and acid, to avoid mineral scaling of the membranes.

We assume there is none or only minor biological activity in the saline formation fluids, as is typical for fluids co-produced with oil and gas compared with ocean water. This allows us to eliminate the need for extensive biological pre-treatment to avoid biofilm formation. Biofilm formation is generally regarded one of the most difficult problems in seawater RO systems (Amjad, 1993).

Many saline formation waters contain significant hydrocarbons, which are known to aggressively foul RO membranes (Fritzmann et al., 2007). Removal methods may be needed if the saline water contains significant hydrocarbons. ( $x x$ We discussed this earlier - need to resolve this).

Since the measured temperature for many reservoir feeds can exceed $100^{\circ} \mathrm{C}$, the saline formation water may need to be chilled to a temperature cool enough to allow treatment using conventional RO membranes. The current limit for long-term use of conventional membranes is around $50^{\circ} \mathrm{C}$, although high-temperature elements are available that can be used up to $70^{\circ} \mathrm{C}$ (Snow et al., 1996). Heat exchangers will therefore be necessary to bring the feed water to within the membrane operating envelope. We include in our costs the use of heat exchangers of a shell and tube design (due to the high pressures involved) and made of 317L stainless steel or better and employed in a split stream formation. The necessary corrosion resistance of the material to be used will be a function of the chloride and sulfide levels in the reservoir fluid.

The split heat exchanger arrangement would cool a portion of the feed using the counter flowing, previously cooled permeate. The second heat exchanger package would treat the remaining hot feed by cooling it with the previously cooled reject.

The inherent heat losses and inefficiencies of this heat transfer arrangement would be supplemented by an auxiliary heat transfer device, which would either be in the form of an air cooled atmospheric exchanger or it would be tied into the power plant cooling system to provide for the additional cooling as needed. In our cost analysis we assume 
air cooling. For the latter arrangement, surplus cooling capacity from the power plant would be required. While there would be some pressure losses associated with the passage through the heat exchange system, the pressure drops across exchangers are typically less than $100 \mathrm{kPa}$.

One area of difference between the two processes is that the design of seawater systems views the amount of feed strictly from an economic point of view. The only treatment product of value is the extracted permeate water. Seawater RO plants strive to maximize recovery in order to reduce the cost per unit volume of permeate for a given degree of pressurization.

The situation is different for conditions where there is significant subsurface pressure (e.g. well confined sequestration reservoirs) because a significant fraction of the energy needed to drive RO can be obtained from the pressurized reservoir. In this case, energy costs, which ordinarily make it most effective to maximize recovery, are less important and allow favorable economics for low recovery. The benefit from low recovery is that it increases membrane longevity by reducing the risk of membrane scaling and lowering the driving pressure. The down side is that one now then has to pump and treat a larger volume of brine in order to produce the same amount of permeate - and equivalent storage space for $\mathrm{CO}_{2}$ in the subsurface. We explored a range of recoveries in our cost analysis.

The last stage of seawater RO is an energy recovery step, where the pressure of the exiting concentrate is recovered and used to either generate electrical energy or to pressurize the incoming feed. The energy recovery device is not needed for our saline formation water process because the residual pressure is needed to re-inject the concentrate back into the formation. In fact, the pressure of the concentrate may need to be increased, depending on where it is injected into the formation.

\subsection{Saline formation water desalination costs}

A list of the treatment components for seawater compared to saline formation waters is given in Table 1. These are the unit processes and operations that are considered in our cost analysis that follows. The system capital costs include the following major components:

1. High pressure piping from the well head to the treatment system. The piping would require a material quality of $316 \mathrm{~L}$ or better to minimize corrosion.

2. Activated carbon pretreatment to remove organics (oil and grease), unlike conventional seawater $\mathrm{RO}$, these systems will have to accommodate high feed pressure.

3. Heat exchanger to reduce the feed temperature to $50^{\circ} \mathrm{C}$,

4. Cartridge filter system 
5. Chemical injection system for scale inhibitor or acid

6. RO skids, pressure vessels, and membranes

7. System instrumentation and control (I\&C)

8. System piping valves, controls \& instruments

9. Forward flush and clean-in-place systems

10. Tankage for chemicals and permeate water

11. Re-pumping station for reject (concentrate) deep well injection

12. Pretreatment system for deep well injection

13. Civil works, equipment housing and installation costs

14. One spare RO train for standby assurance

We did not include costs for land acquisition or for construction of the brine well field, which includes costs associated with drilling production and reinjection wells.

Operating and maintenance costs include:

1. Consumable chemicals, filter replacements, etc.

2. Hazardous wastes disposal costs

3. RO membrane replacement; depreciation ranging over two (2) to four (4) years, depending on the percent recovery of the system.

4. Labor costs for supervisor/engineer, operators and technician. Salaries estimated with an overhead factor of two (2).

5. Maintenance estimated at $3 \%$ of capital annually.

The capital and operating costs were analyzed for several system sizes and recoveries. Base models for costing were developed for 2 and 4 million gallons per day (MGD) systems, which were then used to estimate the costs for the 6 and 8 MGD systems, using exponential escalation factors. Elements, vessels, and piping were estimated by actual cost and quantity or in the case of piping per pound costs for calculated pipe diameters and thickness.

RO costs were estimated for $45 \%, 40 \%, 35 \%, 30 \%, 25 \%$ and $15 \%$ percent recoveries defined as percent permeate extracted from the feed. As described above, percent recovery is a function of the incoming feed salinity. Since processing ceiling is dictated by the maximum allowable membrane operating pressure, the osmotic pressure of the reject stream becomes the limiting factor. The higher the feed salinity the lower the percent recovery before the maximum allowable pressure is reached. Operating pressure is comprised of the osmotic pressure of the concentrate plus the hydraulic pressure loss created by the membrane barrier, plus a driving pressure to push water through the membrane.) At a feed TDS of $60,000 \mathrm{mg} / \mathrm{L}$, recovery may be limited to 15 to $20 \%$ recovery for maximum operating pressures of $8.3 \mathrm{MPa}(1,200 \mathrm{psi})$. 
Table 2 summarizes the major costs and cost factors employed in developing the system costs. Results for the scenarios are displayed in Table 3 and Figures 8 and 9. Figure 8 shows that levelized water costs per acre-foot of permeate vary from about $\$ 450$ to $\$ 1000$ (32-81 $\not$ cubic meter, one acre foot is 1233 cubic meters), and that the costs decrease as the size of the operation increases. [FIGURE 8] In addition, there is a cost effective recovery point (minimum) in plots of recovery vs. cost.

Most importantly, however, the lower recovery options are economically close to the higher recovery options - that is, the curve is fairly flat. With conventional pumped systems the curve is much more pronounced, greatly favoring higher recovery. As mentioned above, this is because the additional costs associated with moving and pressurizing additional feed is now reduced because the pressurization is no longer a large operating expense. In this scenario we assume that the energy to pressurize the fluid is supplied by the reservoir (which we believe may be obtainable for some but not likely all storage reservoir scenarios).

Although we have assumed a fluid salinity similar to that of seawater, our estimated costs are not highly sensitive to salinity. This is because we assume the energy for desalination comes mainly from the existing reservoir pressure field and is not a major component of the operating cost. In a conventional desalination system, an increase in salinity makes the process more expensive due to the need for additional energy to operate the system at higher pressures. For this reason, we believe our estimated costs are fairly representative for the range of fluid salinities for which an essentially conventional RO process can be used (i.e. 10,000-85,000 mg/L TDS).

Figure 9 directly compares the costs for a system using reservoir pressure to drive the $\mathrm{RO}$ process with an identical system using high-pressure pumps. [FIGURE 9] The difference between the curves reflects the estimated cost of energy to drive the desalination system. Note also the pumped system shows a steeper cost vs. recovery curve.

One of the items to warrant further review is the problem of optimizing the front end heat exchanger system used to reduce the reservoir fluid's temperature for RO processing. As described above, a cooling device to accomplish the necessary heat reduction might consist of a split heat exchanger arrangement, which will have to be augmented via a secondary heat reduction source. The specific nature of this supplementary heat rejection will have to be considered. The technical and cost impact of coupling the heat reduction with the power plant's cooling system vs. a stand-alone system that uses atmospheric cooling, possibly augmented by spray evaporation, must be made. Since this would consume RO permeate, thereby reducing the amount of recovered water for power plant use, it may be a significant factor to consider. 


\subsection{Conclusions}

Our analysis indicates that RO plants for CCS brines that are similar in salinity to seawater can be built and operated for about half of the cost of seawater desalination if sufficient over-pressure (from $\mathrm{CO}_{2}$ injection) exists to supply the pressure needed to drive reverse osmosis. Over $40 \%$ of subsurface brines co-produced with fossil fuels have salinities at or below seawater. For a fresh water production of six million gallons per day (about 23,000 cubic meters or about 18 acre feet), we estimate costs of about 32 to $40 \phi$ per cubic meter permeate produced. Without well-head energy recovery, the costs are from 60 to $80 \phi$ per cubic meter permeate, similar to conventional seawater desalination. This analysis includes all surface facilities, transfer pumps, and piping, but does not consider the cost of the brine extraction and reinjection wells, which will be site dependent.

The costs for membrane desalination of sedimentary brines that are higher in salinity than our upper limit of $85,000 \mathrm{mg} / \mathrm{L}$ will be larger. It is currently impossible to estimate these costs because membrane treatment technologies that operate in that salinity range do not exist. However, we believe it is likely that improved RO technologies capable of desalinating more concentrated brines would quickly become available if sufficient demand existed. As mentioned above, both the pressure and temperature limits are due to support materials and are not intrinsic limitations of the semi-permeable polyamide membrane. High temperature-pressure RO membranes could be constructed with improved support materials. For these reasons, we expect the treatment costs for higher salinity brines to be only modestly higher than those for seawater after allowing for higher pressures and lower recoveries.

The amount of fresh water produced by our process is significant. For example, a typical $1 \mathrm{GW}$ coal plant emits more than $7 \mathrm{MtCO} 2 /$ year. A well-designed capture system might provide $6 \mathrm{MtCO} 2$ for sequestration. Sequestered at a depth of 300 meters, this $\mathrm{CO}_{2}$ would displace about 8 million cubic meters of water per year, or about 22,000 cubic meters per day. Reverse osmosis treatment of that brine with a recovery of $40 \%$ would annually produce about 3.2 million cubic meters of fresh water, which could serve the needs of 10,000 homes, irrigate 2000 acres of cropland, or provide half of the water volume usage of a typical $1 \mathrm{GW}$ IGCC power plant, based on a plant use of about 2000 liters/MW-h (Grubert and Kitasei, 2010).

An additional benefit of our process is that strategic withdrawal and reinjection of saline aquifer brines will allow manipulation of the location and migration of the $\mathrm{CO}_{2}$ pool in the subsurface. This could be accomplished by using brine injection/withdrawal to alter the subsurface pressure field so as to affect the pressure gradient surrounding the $\mathrm{CO}_{2}$ pool in the desired way. This ability to manipulate the $\mathrm{CO}_{2}$ by imposing pressure gradients 
has the potential to substantially reduce the inherent risk of geologic sequestration of $\mathrm{CO}_{2}$.

Finally, site selection for saline aquifers suitable for disposal of carbon dioxide and for which brine removal increases reservoir capacity should include some consideration of the fluid salinity, because lower salinity fluids are less costly to desalinate.

\section{Acknowledgements}

Financial support for this work was provided by DOE through the National Energy Technology Laboratory. We thank Sean Plasynski and Andrea McNemar for their help and advice. We also thank Geoffrey Thyne of the Enhanced Oil Recovery Institute at the University of Wyoming, George Breit of the USGS, and Julio Friedmann of LLNL for helpful discussions about produced waters.

Prepared by LLNL under Contract DE-AC52-07NA27344. 


\section{References}

Amjad, Z. 1993, Reverse Osmosis: Membrane technology, water chemistry, and industrial applications: Springer, $384 \mathrm{p}$

Bachu, S., 2008. CO2 storage in geological media: Role, means, status, and barriers to deployment. Progress in Energy and Combustion Science, 34: 254-273.

Baker, R. W., 2004. Membrane Technology and Applications, 2nd ed.; John Wiley \& Sons, Ltd.: Chichester.

Breit, G.N., 2002. Produced Waters Database: U.S. Geological Survey provisional database. Downloadable from: http://energy.cr.usgs.gov/prov/prodwat/index.htm.

Buros, O. K., 2000. The ABCs of Desalting. $2^{\text {nd }}$ edition, International Desalination Association, Topsfield, Massachusetts, U.S.A.

Buscheck, T.A., Hao, Y., Tompson, A., Sun, Y., Aines, R.D., Wolery, T., Bourcier, W.L., Burton, E., Waggoner, J., and Friedmann, S.J., 2011. Combining brine extraction, desalination, and residual brine reinjection with $\mathrm{CO}_{2}$ storage in saline formations: Implications for pressure management, capacity, and risk mitigation. Energy Procedia 4, 4283-4290.

Carr, T.R., Rich, P.M., and Bartley, J.D., 2007. The NATCARB geoportal: linking distributed data from the Carbon Sequestration Regional Partnerships. Journal of Map and Geography Libraries "Special Issue on Department of Energy (DOE) Geospatial Science Innovations" 4(1):131-147.

Court, B, Celia, M.A, Nordbotten, J.M, and Elliot, T.R., 2011. Active and integrated management of water resources throughout $\mathrm{CO} 2$ capture and sequestration operations. Energy Procedia 4, 4221-4229.

Dooley J.J., and Davidson, C.L., 2010. A Brief Technical Critique of Economides and Ehlig-Economides 2010 "Sequestering Carbon Dioxide in a Closed Underground Volume". PNNL-19249, Pacific Northwest National Laboratory, Richland, WA,

Dow Water Solutions, 2009. FILMTEC ${ }^{\text {TM }}$ Reverse Osmosis Membranes Technical Manual. Form No. 609-00071-1009. Dow Water Solutions, Midland, MI. Downloadable from: http://msdssearch.dow.com/PublishedLiteratureDOWCOM/dh_0344/0901b8038034 4689. pdf?filepath=liquidseps/pdfs/noreg/609-00071.pdf. 
Ehlig-Economides, C., and Economides, M.J., 2010. Sequestering carbon dioxide in a closed underground volume. Journal of Petroleum Science and Engineering 70, 123-130.

Frenkel, V. S., 2011. Chapter 6 in, Desalination, Trends and Technologies, Michael Schorr, ed., InTech, February, 2011.

Fritzmann, C., Lowenberg, J., Wintegns, T., and Melin, T., 2007, State-of-the-art of reverse osmosis desalination. Desalination 216, 1-76.

Greenberg, J. P., and N. Møller, N., 1989. The prediction of mineral solubilities in natural waters: A chemical equilibrium model for the Na-K-Ca-Cl- $\mathrm{SO}_{4}-\mathrm{H}_{2} \mathrm{O}$ system to high concentration from 0 to $250^{\circ} \mathrm{C}$. Geochimica et Cosmochimica Acta 53, 2503-2518.

Grubert, E. and Kitasei, S., 2010. How energy choices affect fresh water supplies: A comparison of U.S. coal and natural gas. Worldwatch Institute Briefing Paper 2.

Hilal, N., Al-Zoubi, H., Darwish, N. A., Mohammed, A. W., and Arabi, M. A. 2004. A comprehensive review of nanofiltration membranes: Treatment, pretreatment, modeling, and atomic force microscopy. Desalination, 170, 281-308.

Karagiannis, I. C. and Soldatos, P. G., 2008, Water desalination cost literature: review and assessment. Desalination 223, 448-456.

Kharaka, Y. K., and Hanor, J. S., 2007. Deep fluids in the Continents: I. Sedimentary Basins, Chapter 5.16 in Treatise on Geochemistry, H. Holland and K. Turekian, eds., p. 1-48., Elsevier.

Khawaji, A. D., Kutubkhanah, I. K., and Wie, J-M., 2008, Advances in seawater desalination technologies, Desalination 221, 47-69.

Matsuura, T., 2001. Progress in membrane science and technology for seawater desalination - a review. Desalination 134, 47-54.

Moch, I., 2008. WT Cost II. Modeling the capital and operating costs of thermal desalination processes utilizing a recently developed computer program that evaluates membrane desalting, electrodialysis, and ion exchange plants. U.S. Bureau of Reclamation Desalination and Water Purification Research and Development Program Report No. 130.

National Research Council, 2008. Desalination: A National Perspective, National Academies Press, http://www.nap.edu 
Pabalan, R.T. and Pitzer, K.S., 1987. Thermodynamics of concentrated electrolyte mixtures and the prediction of mineral solubilities to high temperatures for mixtures in the system Na-K-Mg-Cl-SO ${ }_{4}-\mathrm{OH}-\mathrm{H}_{2} \mathrm{O}$. Geochimica et Cosmochimica Acta 51, 2429-2443.

Rutqvist, J., J. T. Birkholzer, J. T., Cappa, F., and Tsang, C.-F., 2007. Estimating maximum sustainable injection pressure during geological sequestration of $\mathrm{CO}_{2}$ using coupled fluid flow and geomechanical fault-slip analysis. Energy Conversion Management 48, 1798-180.

Snow, M. D., de Winter, Buckingham, R., Campbell, J., and Wagner, J., 1996. New techniques for extreme conditions: High temperature reverse osmosis and nanofiltration. Desal 105, 57-61.

Surdam, R.C., Jiao, Z., Stauffer, P., and Miller, T., 2011. The key to commercial-scale geological CO2 sequestration: Displaced fluid management. Energy Procedia 4, 4246-4251.

Wolery, T.J., and Jarek, R.L., 2003. Software User's Manual, EQ3/6, Version 8.0. Civilian Radioactive Waste Management System Management \& Operating Contractor. 10813-UM-8.0-00. Prepared for U.S. Department of Energy, Office of Civilian Radioactive Waste Management, Las Vegas, Nevada. 


\section{Figure captions}

Figure 1. Schematic of reverse osmosis membrane geometry. Example pressures of feed, concentrate and permeate are shown to illustrate relative pressures during conventional treatment of seawater.

Figure 2. Osmotic pressure for salt solutions as a function of system recovery.

Figure 3. Histogram of salinities of produced waters in the U.S. from depths greater than 3000 feet. Data from the U.S.G.S. data base of produced waters (Breit, 2002).

Figure 4. Histogram of hardness $(\mathrm{Ca}+\mathrm{Mg}$ expressed as $\mathrm{mg} / \mathrm{L} \mathrm{Ca})$ for produced waters in the U.S. using data from the U.S.G.S. data base of produced waters (Breit, 2002).

Figure 5. Predicted mineral precipitation as a function of water removal due to reverse osmosis at $50^{\circ} \mathrm{C}$ in a batch system for (a) seawater brine $(35,000 \mathrm{mg} / \mathrm{L})$; (b) Sublette County Wyoming \#3 brine $(86,000 \mathrm{mg} / \mathrm{L})$, and (c) Sublette County Wyoming \#2 brine $(24,500 \mathrm{mg} / \mathrm{L})$. Minor calcite $\left(\mathrm{CaCO}_{3}\right)$ precipitates at the start (not shown) and persists for all three fluids.

Figure 6. Predicted osmotic pressure in residual brine as a function of water removal due to reverse osmosis at $50^{\circ} \mathrm{C}$ in a batch system. (a) seawater; (b) Sublette County Wyoming \#3 brine (86,000 mg/L), (c) Sublette County Wyoming \#2 brine $(24,500$ $\mathrm{mg} / \mathrm{L})$. The "Pitzer" curves show the osmotic pressure as obtained from the activity of water calculated from a thermodynamic model using Pitzer's equations incorporated in the EQ3/6 modeling code. The Dow model uses the van't Hoff equation discussed in text.

Figure 7. Comparison of major treatment steps in conventional high-pressure seawater desalination vs. low-recovery desalination of saline formation waters.

Figure 8. Comparison of estimated levelized costs per acre-ft of brine at 4 different production rates in million gallons permeate per day (MGD).

Figure 9. Comparison of levelized cost of water desalination for pressurized brines from CCS sites (where we assume well-head pressure is adequate to drive RO system) vs. cost for conventional seawater RO that includes energy needed for high pressure pumps. 
Figure 1

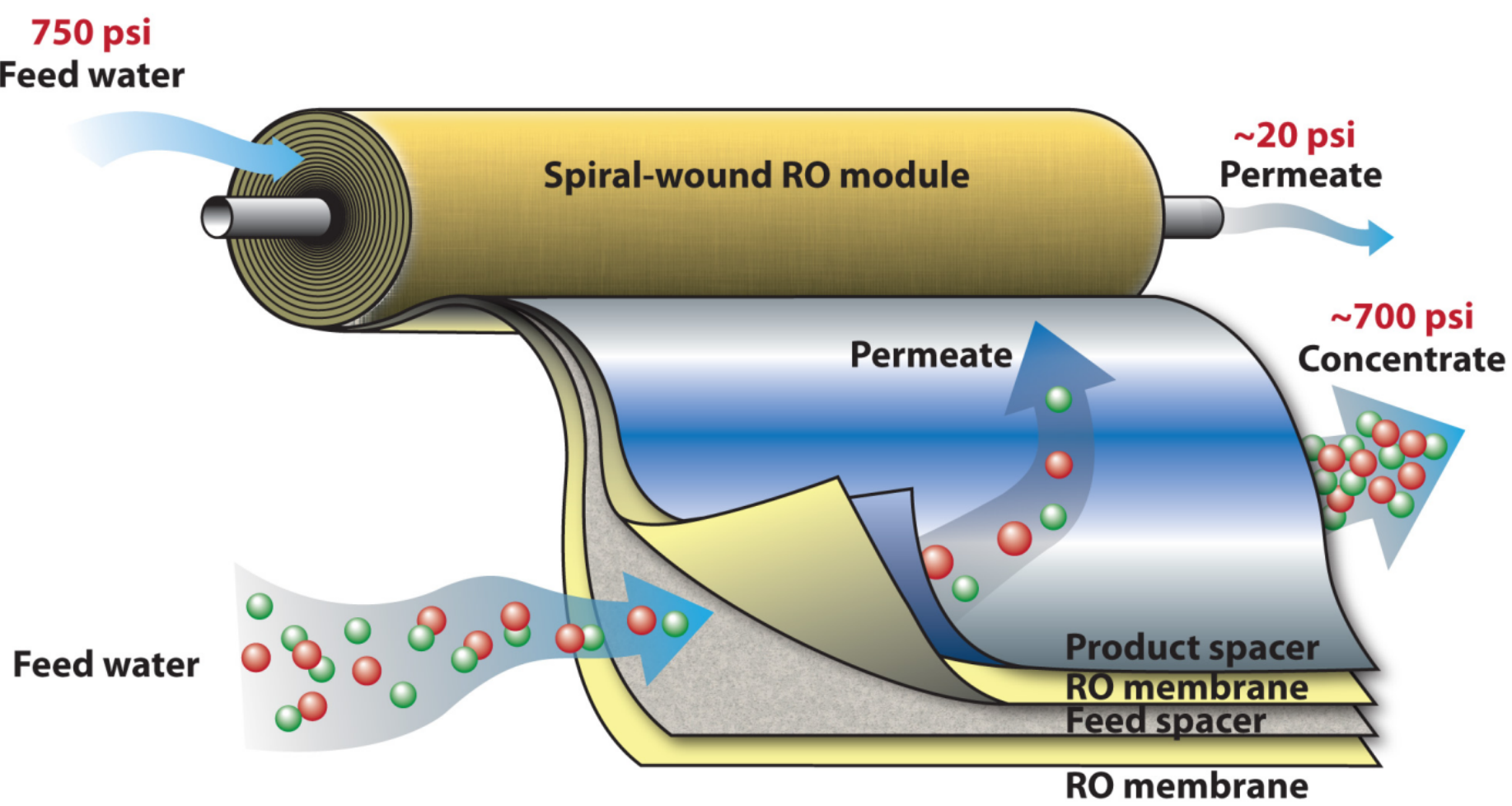


Figure 2

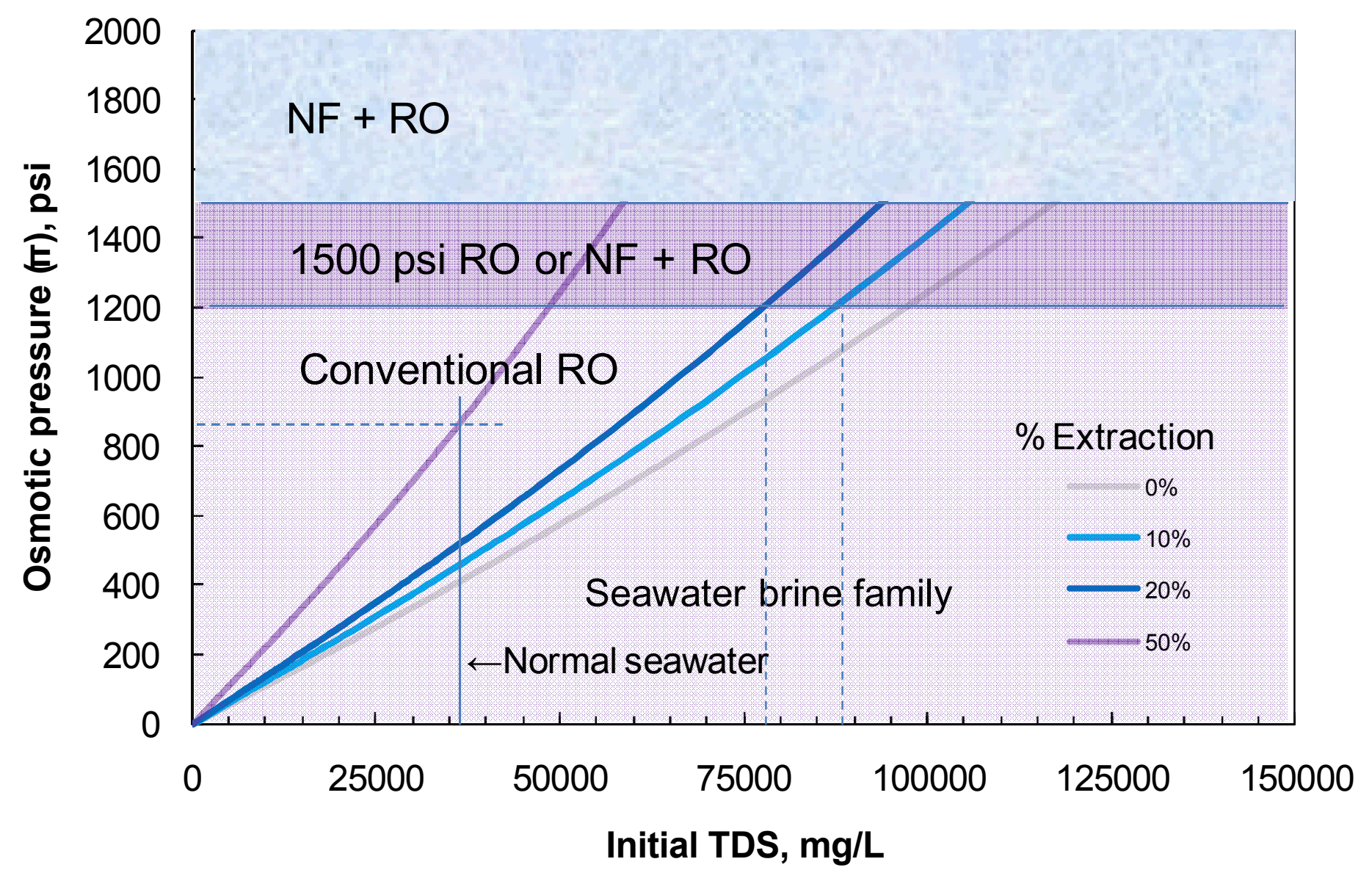


Figure 3

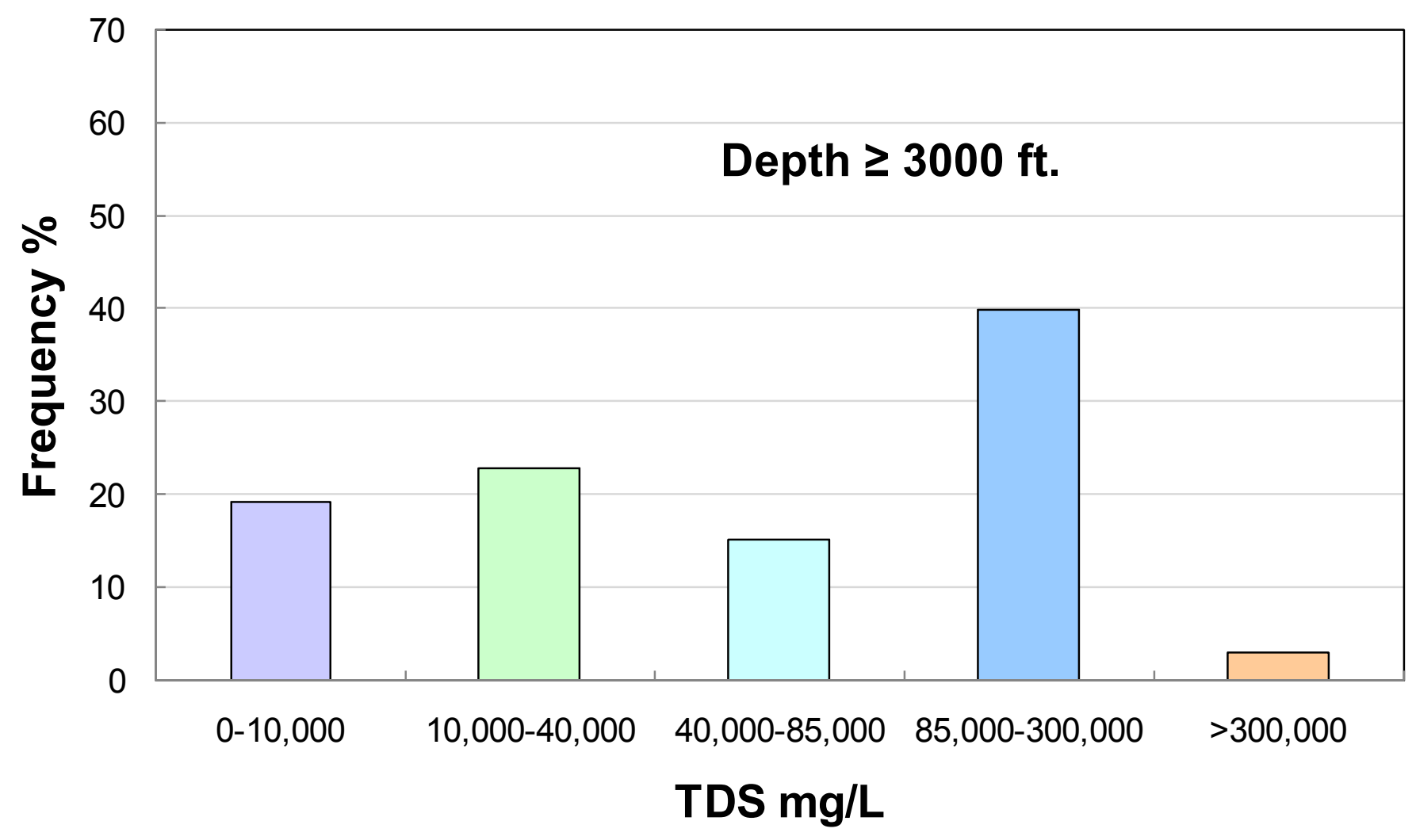


Figure 4

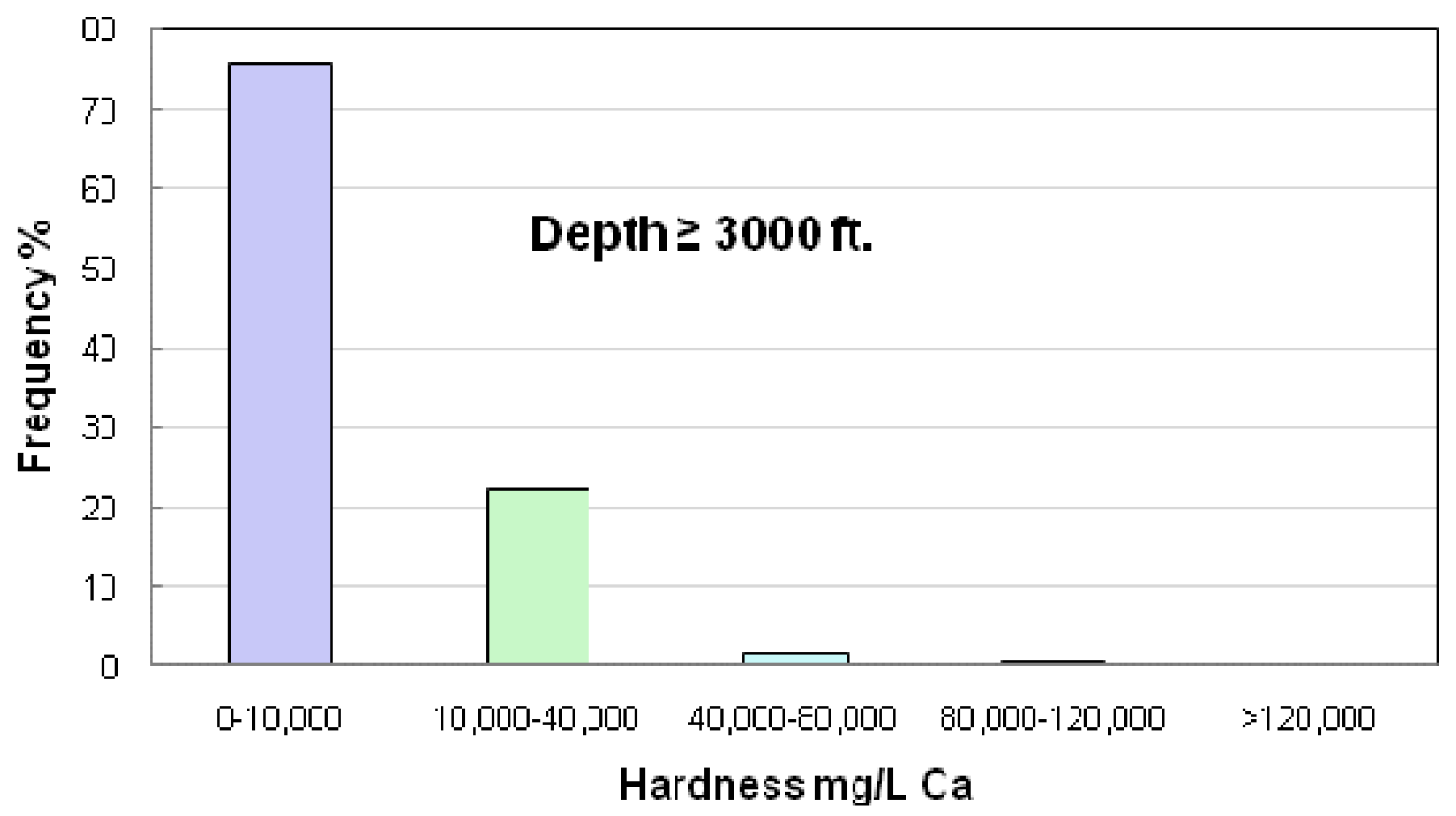


Figure 5
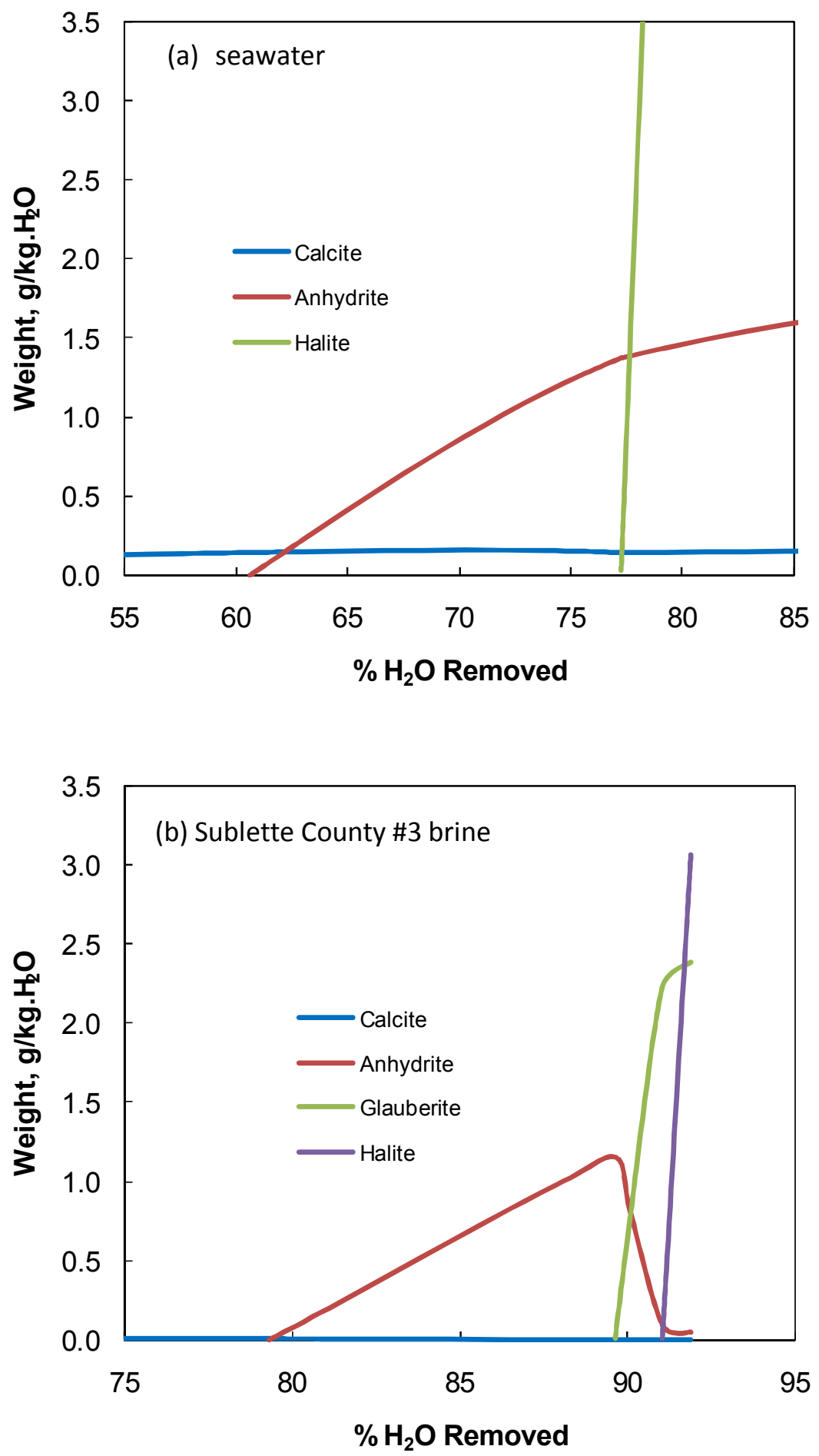


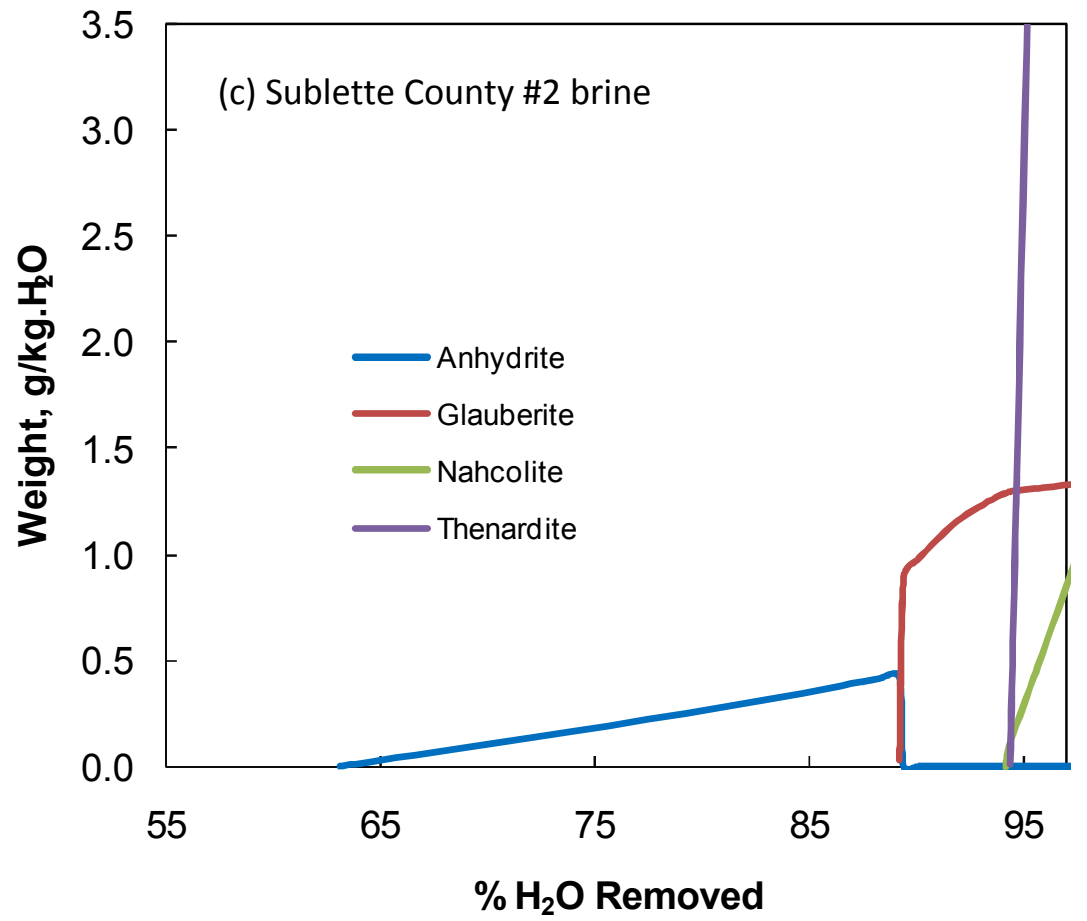


Figure 6
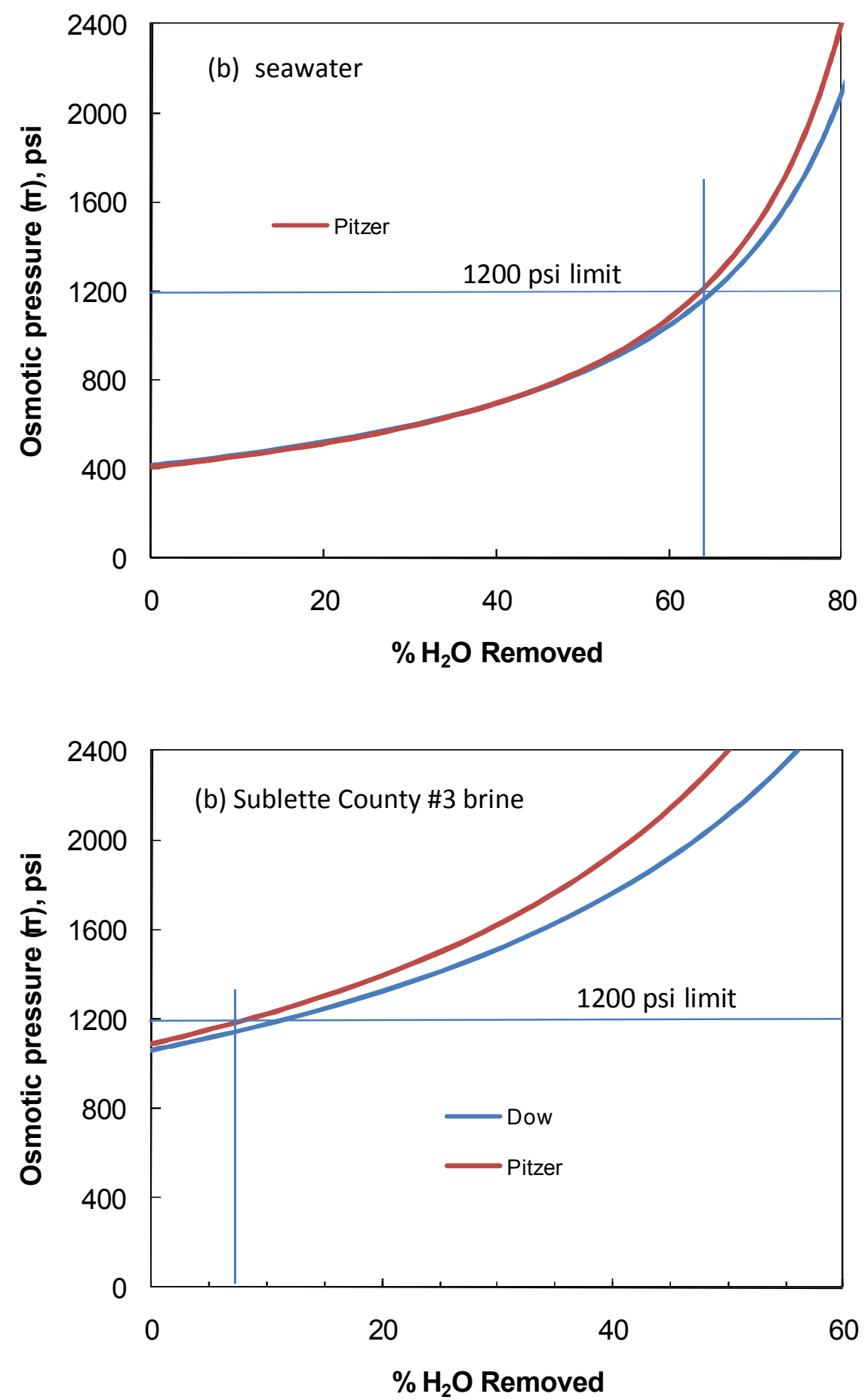


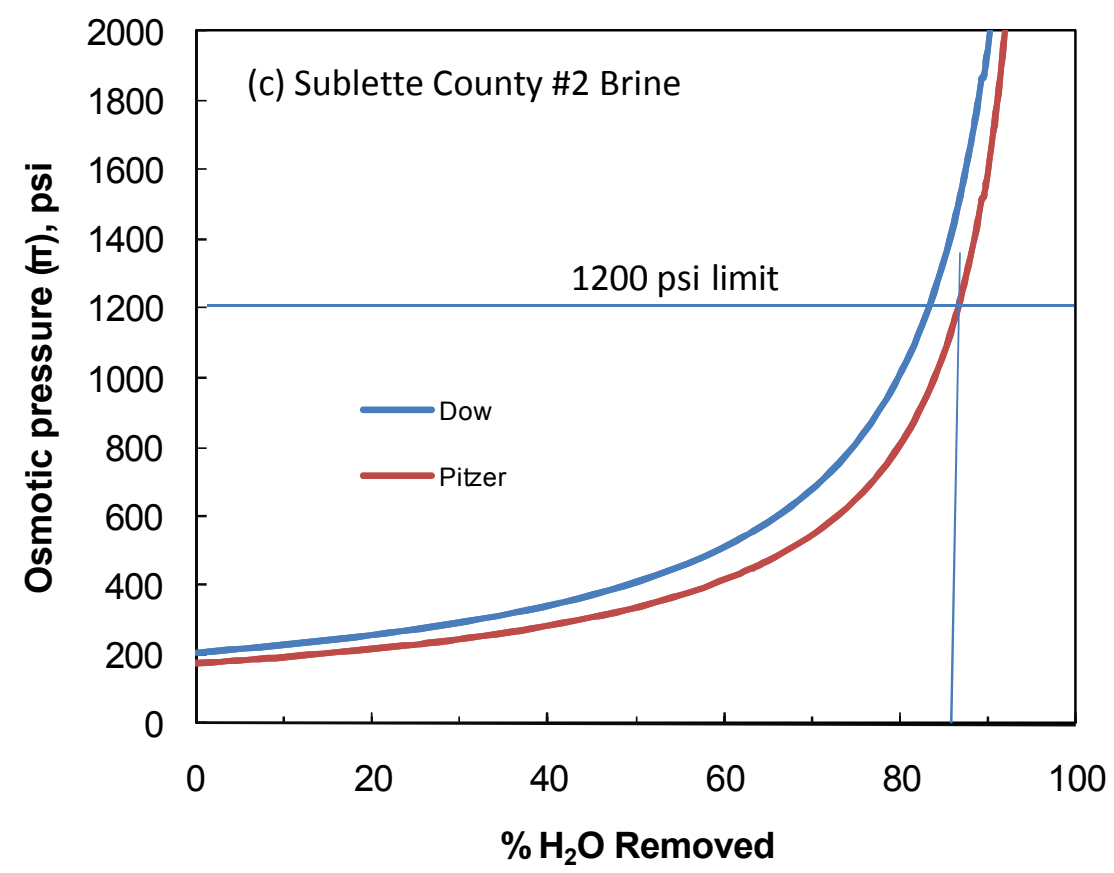


Figure 7

\section{Sea water}

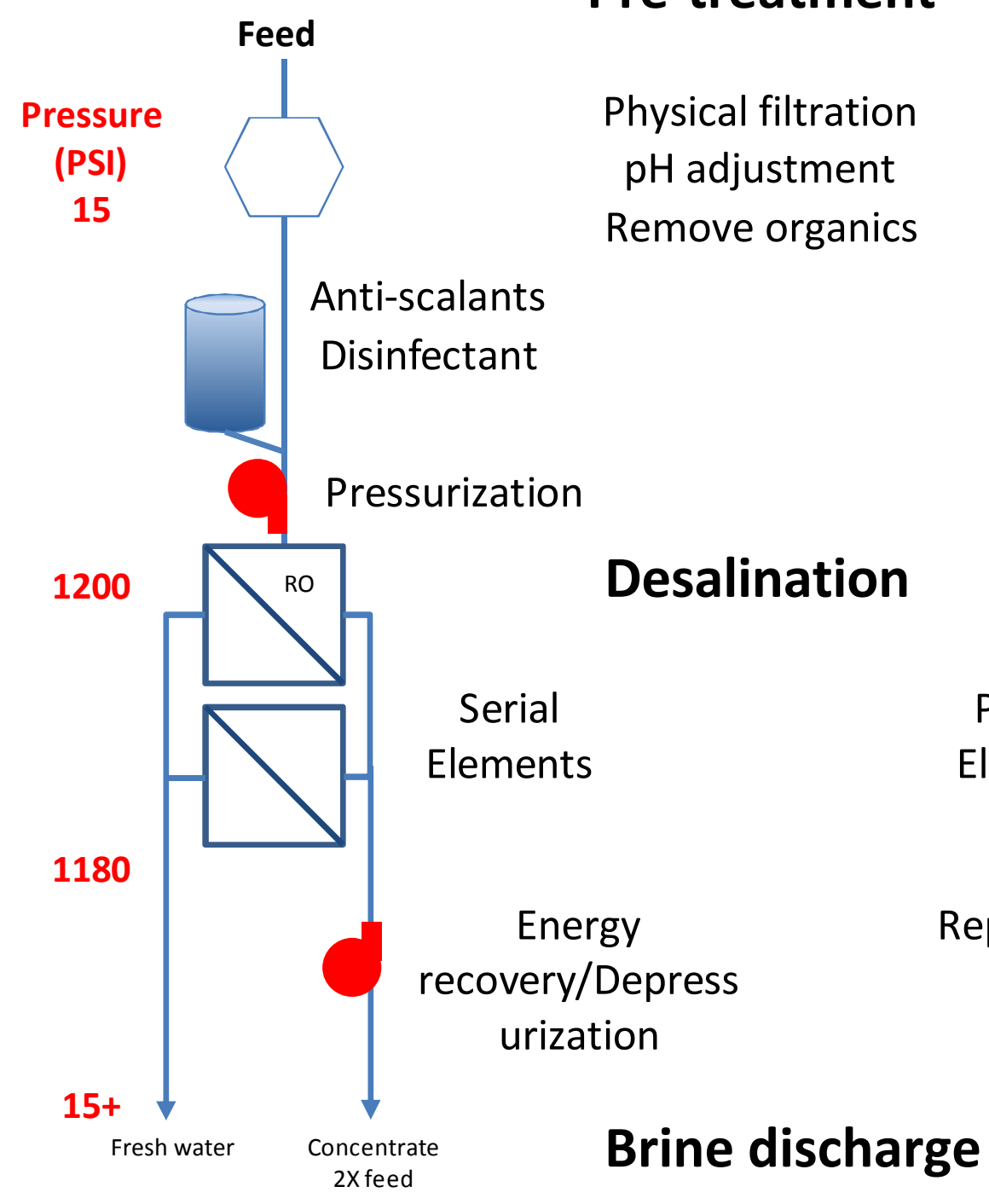

Ocean
Saline aquifer fluid Feed

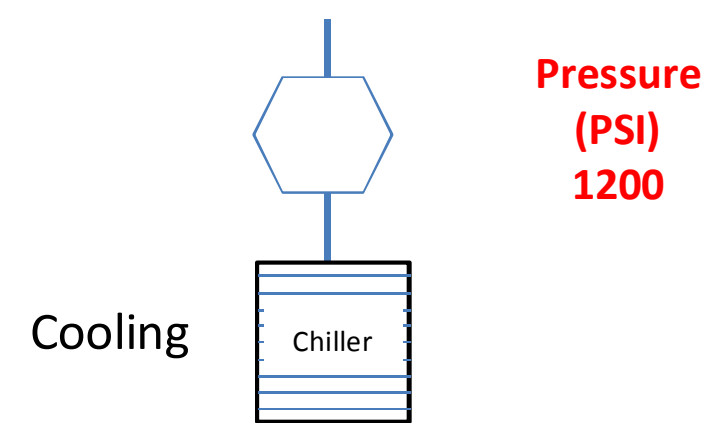

Parallel Elements

Repressurization

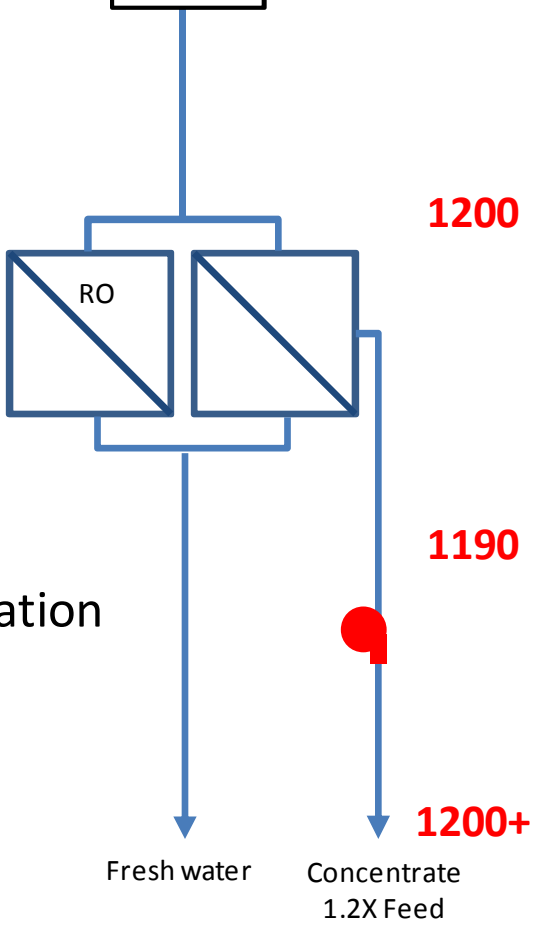

Saline aquifer 
Figure 8

\section{Levelized Cost of Water vs. Recovery}

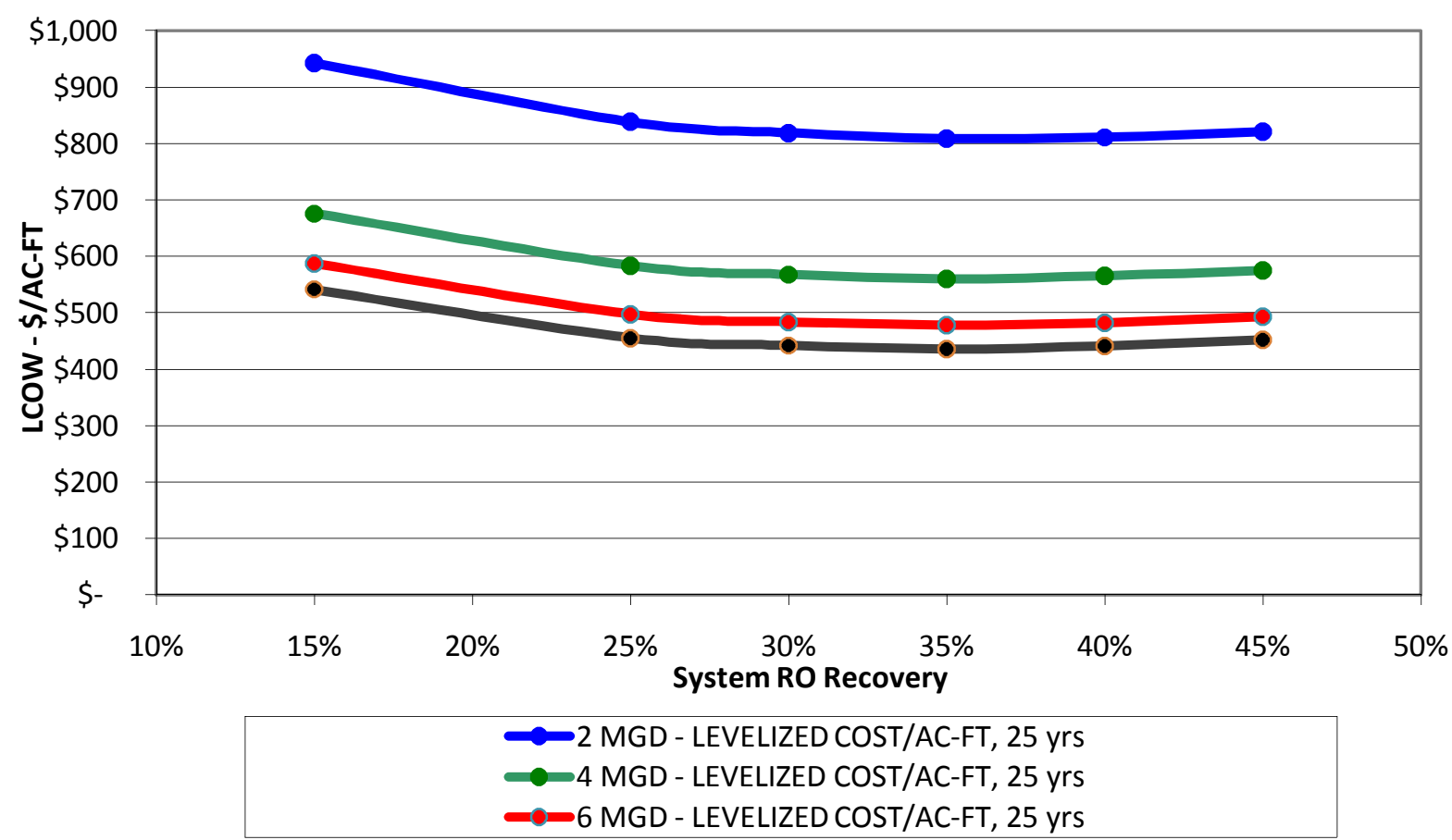


Figure 9

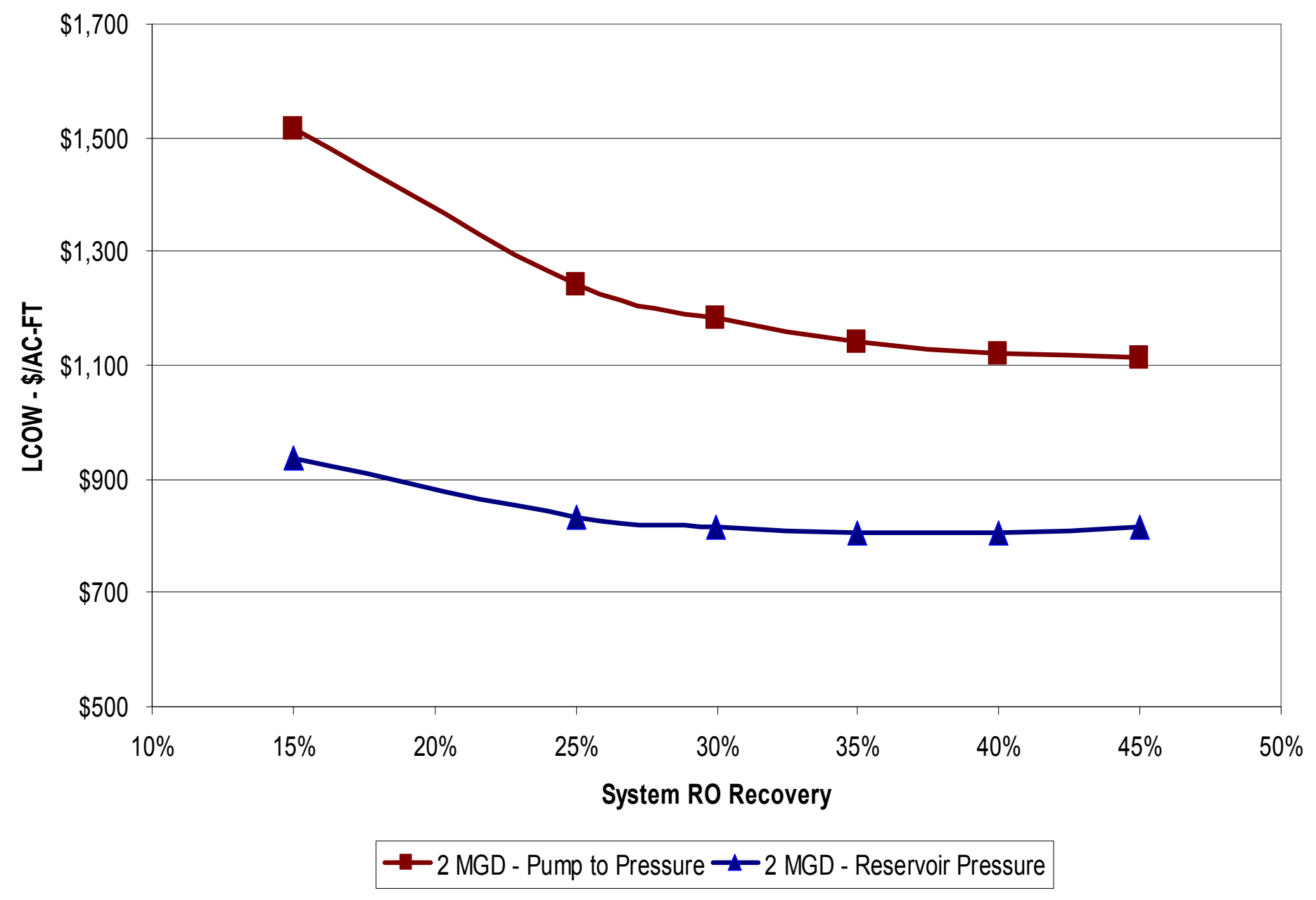


Table 1. Conventional seawater vs. saline formation water reverse osmosis treatment systems.

\begin{tabular}{|c|c|c|}
\hline RO System Major Component / Items & Conventional SW Systems & Reservoir Treatment System \\
\hline \multicolumn{3}{|l|}{ EQUIPMENT } \\
\hline High pressure feed piping & $\begin{array}{l}\text { Only necessary after the high pressure } \\
\text { pump }\end{array}$ & Starting from the well head \\
\hline High pressure reject piping & $\begin{array}{l}\text { Only to back pressure control valve, i.e. } \\
\text { skid boundary }\end{array}$ & $\begin{array}{c}\text { Return line to the deep well injection } \\
\text { point }\end{array}$ \\
\hline Intake / feed structure & Open intake structure or sea wells & Reservoir wells \\
\hline Pretreatment system & Multi-media filter or micro-filter & Activated carbon filter \\
\hline Feed pumping system & Needed from feed source to RO skid & Not needed - Use well head pressure \\
\hline Pretreatment system & Cartridge filters & Cartridge filters \\
\hline Heat exchanger & None & Yes. Reduce feed temperature to $50^{\circ} \mathrm{C}$ \\
\hline Chemical Injection system - bio control & $\begin{array}{l}\text { Yes - for bio control followed by } \\
\text { reducing agent }\end{array}$ & Not needed \\
\hline $\begin{array}{l}\text { Chemical Injection system - scale } \\
\text { control }\end{array}$ & $\begin{array}{l}\text { Yes - scale inhibitor for calcium } \\
\text { carbonate }\end{array}$ & $\begin{array}{l}\text { Yes - scale inhibitor for calcium } \\
\text { carbonate and/or calcium sulfate }\end{array}$ \\
\hline High pressure pump & Yes (most costly item of RO skid) & No - Use well head pressure \\
\hline Energy recovery device & Yes - typically used for larger systems & $\begin{array}{c}\text { No - keep reject at maximum pressure } \\
\text { for reinjection }\end{array}$ \\
\hline RO pressure vessels (PV) & Same for equal permeate capacity & Same for equal permeate capacity \\
\hline RO membranes & Conventional seawater membranes & Conventional seawater membranes \\
\hline Array - configuration & $\begin{array}{c}\text { Single pass } \\
7 \text { elements per PV }\end{array}$ & $\begin{array}{c}\text { Single pass } \\
\text { 7 elements per PV }\end{array}$ \\
\hline Percent recovery & $\begin{array}{c}\text { Ranges between } 30 \text { to } 50 \% \text {, depending } \\
\text { on seawater concentration, system size } \\
\text { and energy costs }\end{array}$ & $\begin{array}{c}\text { Ranges between } 15 \text { to } 45 \% \text {, depending } \\
\text { on reservoir feed concentration and } \\
\text { composition }\end{array}$ \\
\hline System I\&C & Similar to reservoir system & Similar to seawater system \\
\hline MCC/VFD & $\begin{array}{l}\text { Includes electrical supply for high HP } \\
\text { pump(s) }\end{array}$ & $\begin{array}{c}\text { Same as conventional SW system, with } \\
\text { exception of the high HP pump(s), i.e. } \\
\text { no VFD needed }\end{array}$ \\
\hline Valves, controls \& Instrumentation & Similar to reservoir system & $\begin{array}{c}\text { Similar to seawater system, except high } \\
\text { pressure pump associated valving and } \\
\text { controls }\end{array}$ \\
\hline Tanking & Similar to reservoir system & Similar to seawater system \\
\hline Deep well injection & Reject typically goes to seawater outfall & Deep well injection required \\
\hline Civil works & Very site dependent & Very site dependent \\
\hline \multicolumn{3}{|l|}{ OPERATIONS } \\
\hline Operating & $\begin{array}{l}\text { Similar to reservoir system except no } \\
\text { deep well injection }\end{array}$ & $\begin{array}{l}\text { Similar to seawater system except no } \\
\text { high pressure pump(s) and energy } \\
\text { recovery, but use of deep well injection } \\
\text { for reject concentrate }\end{array}$ \\
\hline Energy consumption & $\begin{array}{l}\text { Energy to deliver feed to high pressure } \\
\text { pumps and then raise to } \sim 1000 \mathrm{psi}\end{array}$ & $\begin{array}{l}\text { Similar to seawater system without the } \\
\text { feed and process pumping. Deep well } \\
\text { injection pumping energy required. }\end{array}$ \\
\hline $\begin{array}{l}\text { Chemicals consumption, including } \\
\text { membrane cleaning }\end{array}$ & Similar to reservoir system & Similar to seawater system \\
\hline Maintenance as \% of capital & Similar to reservoir system & Similar to seawater system \\
\hline
\end{tabular}


Table 2. Major Costs and Cost Factors for RO Treatment Systems.

\begin{tabular}{|l|c|l|}
\hline Assumed Discount Rate & $7.00 \%$ & \\
\hline Plant Lifetime / Evaluation Period & 25.00 & years \\
\hline Operating Cost escalation, \%/yr & $0.00 \%$ & \\
\hline & & \\
\hline Base Operating Pressure at reference conditions & 1,200 & $\mathrm{psi}$ \\
\hline Base recovery & $40 \%$ & \\
\hline Cleaning, times/year & 0.5 & \\
\hline Chemicals & $\$ 3$ & \\
\hline Consumables & & \\
\hline Activated Carbon & $\$ 30$ & $\$ / \mathrm{ft}^{\wedge} 3$ \\
\hline Filter cartridges & $\$ 4$ & $\$ /$ each \\
\hline Power, Repressurization & $\$ 0.07$ & $\$ / \mathrm{kWh}$ \\
\hline Power. Misc uses & 200.00 & $\mathrm{kWh} / \mathrm{day}$ \\
\hline Labor & & \\
\hline Fringe \& Overhead Multiplier & 2.00 & factor \\
\hline Supervisor & $\$ 150,000$ & Salary \\
\hline Operators & $\$ 60,000$ & Salary \\
\hline Technicians & $\$ 75,000$ & Salary \\
\hline & & \\
\hline Mechanical Maintenance, \% of Capital & $3 \%$ & \\
\hline Length of high pressure piping & 125 & $\mathrm{ft}$ \\
\hline
\end{tabular}


Table 3. Itemization of costs for water desalination plants of 2 and 8 MGD permeate at $40 \%$ water recovery.

\begin{tabular}{|c|c|c|c|c|c|c|c|c|c|c|c|c|c|c|c|}
\hline \multicolumn{2}{|c|}{ Base FEED Flow, MGD } & \multirow{3}{*}{$\begin{array}{l}5.00 \\
2.00 \\
40 \%\end{array}$} & \multicolumn{2}{|l|}{ Product Flow, MGD } & \multicolumn{2}{|l|}{2.0} & \multicolumn{2}{|l|}{2.0} & \multicolumn{2}{|l|}{2.0} & \multicolumn{2}{|l|}{2.0} & 20 & \multicolumn{2}{|r|}{2.0} \\
\hline \multicolumn{2}{|c|}{ Base PRODUCT Flow, MGD } & & Recovery, percent & & $45.0 \%$ & & $40.0 \%$ & & $35.0 \%$ & & $30.0 \%$ & & $25.0 \%$ & & $15.0 \%$ \\
\hline Base Recovery & & & AC-FT/YR & & 2,240 & & 2,240 & & 2,240 & & 2,240 & & 2,240 & & 2,240 \\
\hline \multicolumn{2}{|c|}{ TOTAL DIRECT OPERATING COSTS } & & \$/YR & $\$$ & $1,233,698.29$ & $\$$ & $1,206,483.45$ & $\$$ & $1,189,693.71$ & $\$$ & $1,187,315.32$ & $\$$ & $1,183,468.55$ & $\$$ & $1,251,878.92$ \\
\hline & & & \$/AC-FT & $\$$ & 550.77 & $\$$ & 538.62 & $\$$ & 531.12 & $\$$ & 530.06 & $\$$ & 528.35 & $\$$ & 558.89 \\
\hline \multicolumn{2}{|c|}{ INSTALLED CAPITAL COST, \$/GPD } & & & $\$$ & 3.47 & $\$$ & 3.49 & $\$$ & 3.56 & $\$$ & 3.71 & $\$$ & 3.98 & $\$$ & 4.93 \\
\hline \multicolumn{2}{|c|}{ TOTAL DIRECT CAPITAL } & & & $\$$ & $3,844,576$ & $\$$ & $3,912,316$ & $\$$ & $4,027,492$ & $\$$ & $4,234,852$ & $\$$ & $4,588,768$ & $\$$ & $5,823,751$ \\
\hline \multicolumn{2}{|c|}{ INSTALLED CAPITAL COST } & & & $\$$ & $6,934,334$ & $\$$ & $6,987,133$ & $\$$ & $7,120,062$ & $\$$ & $7,414,175$ & $\$$ & $7,962,181$ & $\$$ & $9,869,483$ \\
\hline & & & & & & & & & & & & & & & \\
\hline \multirow{2}{*}{\multicolumn{2}{|c|}{ NPV of O\&M }} & & & $\$$ & $14,149,698$ & $\$$ & $13,837,562$ & $\$$ & $13,644,994$ & $\$$ & $13,617,716$ & $\$$ & $13,573,596$ & $\$$ & $14,358,217$ \\
\hline & NPV of O\&M + Capital Cost & & & $\$$ & $21,084,032$ & $\$$ & $20,824,694$ & $\$$ & $20,765,056$ & $\$$ & $21,031,891$ & $\$$ & $21,535,777$ & $\$$ & $24,227,701$ \\
\hline NPV of AC-FT/yr & & & NPV AC-FT/Perioc & & 25,691 & & 25,691 & & 25,691 & & 25,691 & & 25,691 & & 25,691 \\
\hline \multicolumn{3}{|c|}{2 MGD - LEVELIZED COST/AC-FT, 25 yrs } & & $\$$ & 821 & $\$$ & 811 & $\$$ & 808 & $\$$ & 819 & $\$$ & 838 & $\$$ & 943 \\
\hline \multicolumn{2}{|c|}{ Base FEED Flow, MGD } & 20.00 & Product Flow, MGD & & 8.0 & & 8.0 & & 8.0 & & 8.0 & & 8.0 & & 8.0 \\
\hline \multicolumn{2}{|c|}{ Base PRODUCT Flow, MGD } & 8.00 & Recovery, percent & & $46.0 \%$ & & $40.0 \%$ & & $35.0 \%$ & & $30.0 \%$ & & $25.0 \%$ & & $15.0 \%$ \\
\hline Base Recovery & & $40 \%$ & AC-FT/YR & & 8,960 & & 8,960 & & 8,960 & & 8,960 & & 8,960 & & 8,960 \\
\hline \multicolumn{2}{|c|}{ TOTAL DIRECT OPERATING COSTS } & & \$/YR & $\$$ & $2,259,846.18$ & $\$$ & $2,142,984.72$ & $\$$ & $2,073,987.88$ & $\$$ & $2,061,919.14$ & $\$$ & $2,041,721.61$ & $\$$ & $2,291,635.95$ \\
\hline & & & \$/AC-FT & $\$$ & 252.22 & $\$$ & 239.18 & $\$$ & 231.48 & $\$$ & 230.13 & $\$$ & 227.88 & $\$$ & 255.77 \\
\hline \multicolumn{2}{|c|}{ INSTALLED CAPITAL COST, \$/GPD } & & & $\$$ & 2.57 & $\$$ & 2.59 & $\$$ & 2.62 & $\$$ & 2.72 & $\$$ & 2.92 & $\$$ & 3.67 \\
\hline \multicolumn{2}{|c|}{ TOTAL DIRECT CAPITAL } & & & $\$$ & $10,609,856$ & $\$$ & $10,796,811$ & $\$$ & $10,996,812$ & $\$$ & $11,530,415$ & $\$$ & $12,499,362$ & $\$$ & $16,138,799$ \\
\hline \multicolumn{2}{|c|}{ INSTALLED CAPITAL COST } & & & $\$$ & $20,594,678$ & $\$$ & $20,756,123$ & $\$$ & $20,947,918$ & $\$$ & $21,757,741$ & $\$$ & $23,349,555$ & $\$$ & $29,354,228$ \\
\hline & & & & & & & & & & & & & & & \\
\hline \multicolumn{2}{|l|}{ NPV of O\&M } & & & $\$$ & $25,918,931$ & $\$$ & $24,578,608$ & $\$$ & $23,787,260$ & $\$$ & $23,648,839$ & $\$$ & $23,417,187$ & $\$$ & $26,283,538$ \\
\hline \multicolumn{2}{|c|}{ NPV of O\&M + Capital Cost } & & & $\$$ & $46,513,609$ & $\$$ & $45,334,730$ & $\$$ & $44,735,177$ & $\$$ & $45,406,581$ & $\$$ & $46,766,742$ & $\$$ & $55,637,766$ \\
\hline NPV of AC-FT/yr & & & NPV AC-FT/Perioc & & 102,763 & & 102,763 & & 102,763 & & 102,763 & & 102,763 & & 102,763 \\
\hline & & & & & & & & & & & & & & & \\
\hline \multicolumn{3}{|c|}{8 MGD - LEVELIZED COST/AC-FT, 25 yrs } & & $\$$ & 453 & $\$$ & 441 & $\$$ & 435 & $\$$ & 442 & $\$$ & 455 & $\$$ & 541 \\
\hline
\end{tabular}




\section{Summary of reply to JGGC-D-00120 editor comments (attached PDF file):}

\section{Page 3}

Qualifiers added throughout the manuscript to statements regarding potential existence of subsurface pressure due to CO2 injection

More details of excluded costs provided

Page 4

Offending statements regarding pressure in well field removed

Page 5

Reference to companion paper removed

References added

Page 6

Pore size range given, along with reference

Page 7

Added cost reference

Added sentence to note lack of organisms in typical formation fluids

Noted reference to left vertical dotted line

Comment to editor: These high pressure membranes are being developed by membrane manufacturers, but this sort of information is not in the refereed journals because of its business sensitivity. I hear this by word-of-mouth. Not sure how to handle this. What do you recommend?

Page 8

Added USGS database size and coverage

Added references as specified

Page 10

Added comment on treatability of brines $>85000$ TDS

Added references

Page 11 
Added reference

Modified temperature assertion for basinal brines

Page 13

Added clarification of what is being considered in cost estimate

Page 14

Caveats associated with assumed subsurface pressure have been inserted. Paragraph re-worded based on reviewer comments.

Page 15

Changes made. Last sentence modified to exclude sites where subsurface pressure increase is not an issue.

Page 19

Changes made, added titles to figures and omitted reference to Big Sky CSP

Page 20

No simple way to modify figure - added details in text to clarify

X-axis adjusted to match in Figures 8 and 9. Y-axis was not changed as compressing it to match Figure 9 made Figure 8 harder to interpret.

\section{Summary of reply to JGGC-D-00120 editor comments (embodied e-mail):}

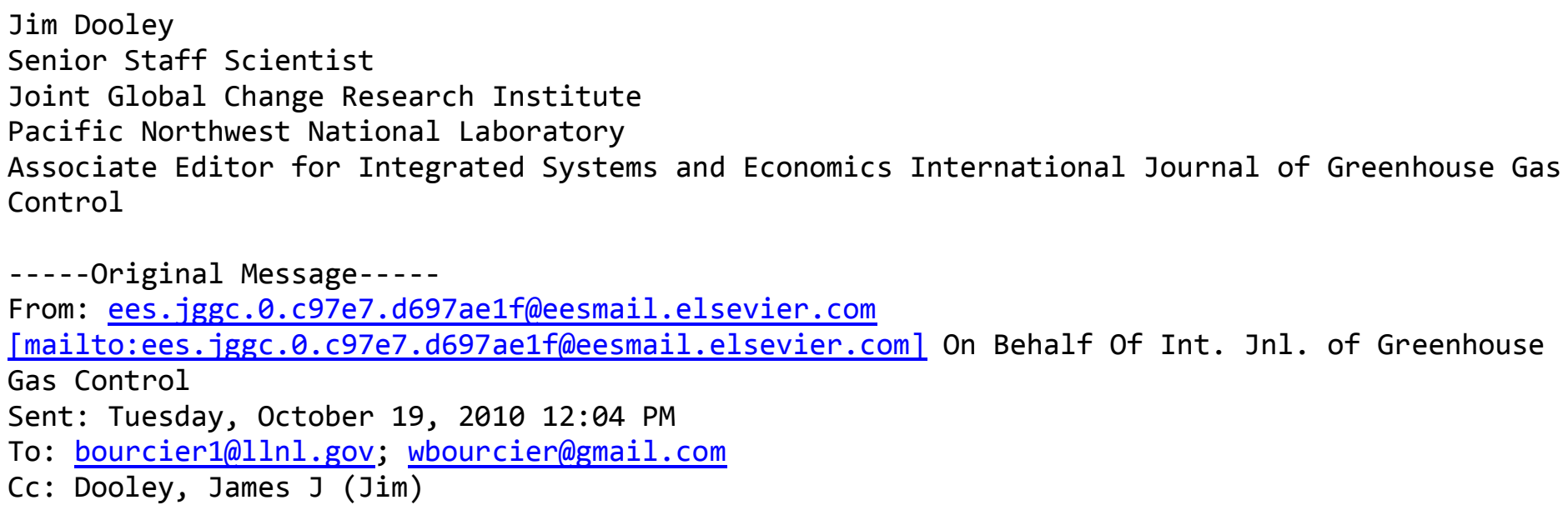


Subject: Your Submission to International Journal of Greenhouse Gas Control

Ms. Ref. No.: JGGC-D-10-00120

Title: Desalination of Formation Waters as a Strategy for Reducing Risk in Geological

Sequestration of Carbon Dioxide International Journal of Greenhouse Gas Control

Dear Dr. William L Bourcier,

The reviewers have commented on your above paper. They indicated that it is not acceptable for publication in its present form and major revisions will need to be implemented. Once these major revisions have been completed to the Editors satisfaction we will consider publishing your paper.

For your reference the comments from the editor and reviewers are listed below for your consideration and action.

Thank you for submitting your work to International Journal of Greenhouse Gas Control. When you are submitting a revised manuscript, please also:

a) outline each change made (point by point) as raised in the reviewer comments AND/OR

b) provide a suitable rebuttal to each reviewer comment not addressed

To submit your revision, please do the following:

1. Go to: http://BLOCKEDees.elsevier.com/jggc/

2. Enter your login details

3. Click [Author Login]

This takes you to the Author Main Menu.

4. Click [Submissions Needing Revision]

I look forward to receiving your revised manuscript.

Yours sincerely,

James J Dooley

Associate Editor

International Journal of Greenhouse Gas Control

Comments from the editors and reviewers:

Editor comments for JGGC-D-10-00120 (jj.dooley@pnl.gov) 
This is a good and very useful paper. If you can address the concerns raised by myself and the peer reviewers, I am confident that we should be able to get this paper into press in short order.

Please consider revising the title of the paper to better match the contents of the paper. To my mind, "A Preliminary Cost and Engineering Estimate for Desalinating Produced Formation Waters Associated with Carbon Dioxide Capture and Storage" (agreed - title changed) is closer to the mark. The current submission does not develop a technical argument for how

desalinzation of formation waters "reduces risk". The paper asserts that point but it is not shown here. What is shown here is a "preliminary" "cost" and "engineering" "estimate." I think this sentence from Section 1 of your paper places things in their proper perspective "An additional benefit is that strategic withdrawal and reinjection of brines may allow manipulation of the location and migration of the $\mathrm{CO} 2$ pool in the subsurface." That is, the process you are looking at here provides and "additional benefit" (i.e., it is not the primary focus of what is presented in the paper) and it "allows" the subsurface plume to be manipulated as a part of good reservoir engineering to assure that CO2 injected into the subsurface stays there. This phrasing of "additional benefit" and "manipulation" seems more consistent with the thrust of this paper and the broad body of technical literature than many of the statements in Section 1 (and elsewhewre) which seem to indicate that unless CCS+desal is done for all DSFs a whole host of very bad things are likely (almost surely) going to happen. (agreed - text modified to make it clear that if we assume reservoir pressure exists, it is an assumption. Our goal is to evaluate how much benefit there is in using it, if present, to power desalination)

I do not believe this paper demonstrates that there would be significant pressure in the formation to deliver to the surface this pressuized feedstream for the desal unit. This is asserted many times. It is not shown here. I therefore think you need to state "assumed cost savings" "assumed pressure head".... I dont see how you can develop that point robustly in this paper as that is a whole body of work that would need to be written up in another paper showing the distance between the $\mathrm{CO} 2$ injector well(s), the brine production well(s), and brine reinjection well(s) and how those change over the life of the CO2 storage field. This is a significant concern of mine. This paper needs to stand by itself. (agreed - text modified in several places to alleviate this concern)

Another concern I have with the paper and in particular Section 1 (but elsewhere) is that the ideal formation for CO2 storage + desal of produced water would appear from the text to be a formation that has a structural trap with a fourway closure. Yet there is nothing in the technical literature that would lead one to assert that is the best or only type of DSF that could be used for $\mathrm{CO} 2$ storage. What I really would like to avoid in your article (as the article is strong enough that it doesn't need to go down this path at all) is a simplistic Economides and Eligh-Economides caricature of $\mathrm{CO} 2$ storage can only happen in a sealed vessel and if you do it in a sealed vessel then you cant put any $\mathrm{CO} 2$ in the formation as it is already "full" and therefore CO2 storage is impossible. I know that is not what you are saying. I would like you to be more clear that you are not saying that. One (but only one) simple thing I think you could do is mention specifically that Gorgon is going to produce water to manage the plume but that Sleipner, Insalah, Snovit do not need to employ this strategy for risk reduction and no one is asserting that those fields are a ticking time bomb that must surely leak someday soon. (agreed - sections that infer this have been qualified or removed, in particular section 1.1 has been edited)

There are many, many, many missing references in the paper. I have noted them in the marked up PDF. In short, unless you are sure that everyone in the relevant technical community 
understands a point, if you are citing a specific value I think there needs to be a reference. "For example, a nanofiltration membrane will allow $\mathrm{Na}$ and $\mathrm{Cl}$ to pass through the membrane freely, while holding back greater than $95 \%$ of the sulfate and calcium." What is the reference for such a specific point "95\%"?(text modified and reference provided) "Seawater desalination costs for membrane-based systems generally vary between $\$ 0.50$ and $\$ 1.00$ per cubic meter of product." Again what is the reference? (reference for this added; 11 references added in total)

Please consider standardizing terminology in the paper. In particular, given that both seawater and the formation brines are going to be saline, I think that term probably should be used unless it is clear to the reader which is being discussed. "Produced saline formation waters from a deep geologic CO2 storage reservoir" is a mouthful and will get tiresome if it is repeated but it is obvious that this is not seawater.

Is "seawater" on word or is it two words "sea water"? The paper uses both. ("seawater" now spelled consistently)

Please make sure that your revised submission adheres to the format guidelines for this journal.

http://BLOCKEDwww.BLOCKEDelsevier.com/wps/find/journaldescription.cws home/709061/authorinstr uctions Please use SI units in the paper. In particular, the paper bounces back at and forth between psi and Mpa, which does nothing to improve the paper's readability. (all pressures now in MPa with psi conversion in parentheses)

Reviewer \#1: Bourcier et al JGGC

Overall the paper is fine. There are several specifics comments that may require minor revisions.

Figure 2 has two vertical lines (text modified to explain which line is being referred to)

pg. 7 - reinjection of produced water is usually for purposes of enhancing continued oil production. (unclear what is being referred to in comment)

Figure $5 c$ should be mentioned in the text. (missing reference added)

Figure 5 contains mineral phases not discussed in the text. (added text to explain significance of these minerals)

bulleted list section with 85,00 to 300,000 TDS should specify "not possible with current technology" to match later discussion of issue in text. (no change made, text suggests some hybrid methods may allow treatment of these fluids)

section 2.1.1 - text suggests that well head pressures of 1200 psi are upper limit in "real system" - what is the basis for this assertion? (Changed text to state that this is the current maximum pressure for RO systems for which there are good cost data) 
section 3.1 - authors calculate scale up of costs using expotential factors, why not additive given the scale up is only a doubling of the basis? (the cost data are based on costs data from real systems, the scale-up cost savings are empirical)

Conlusions - first paragraph gives costs in cubic meters and water production in gallons without conversion, use consistent units. (made units consistent and added conversions)

Calculation of fresh water production associated with $1 \mathrm{GW}$ emissions should specify recovery factor used in calculation. (we are using a recovery of $40 \%$ and units now made consistent just cubic meters of water)

Reviewer \#2: Overall this is a well presented and well researched paper. Management of brine in deep saline formations by producing and treating them can make some otherwise non-viable sites acceptable for geologic storage. The concepts, chemical principles, and assumptions are clearly presented in the paper.

Although, this is an interesting and potentially useful analysis, I have significant concerns whether the technology option presented here will be widely deployed. The primary reason for concern is that almost all saline formation disposal projects that I am aware of have salinity well in excess of seawater. For example, Crenfield and Frio are more than 100,000 $\mathrm{mg} / \mathrm{L}$. All of the midwestern storage projects in the Mt. Simon Sandstone or other lower Paleozoic formations have salinities well in excess of 100,000 and generally exceeding $250,000 \mathrm{mg} / \mathrm{L}$. The authors have chosen to use Wyoming brines as a primary example. However, it is likely that the primary deployment of CCS is likely to be in Gulf Coast and midwestern US or in similar deep high salinity settings. Furthermore, when the brine wells are added to the cost, the total cost will be less attractive compared to seawater desalination. Despite these limitations, it seems that the authors have done a good job of outlining limitations and evaluating the technology for the seawater and similar salinity scenarios. They also mention working on a subsequent paper that will evaluate the hydrogeologic aspects of the brine production. It is hoped that in addition to the general design aspects, this paper will address issues such as potential for preferential channeling of CO2, co-production of $\mathrm{CO} 2$ or other dissolved species with brine, and other environmental or reservoir management challenges.

Agreed. We are laying out the costs and limitations, and are not making further judgements as to likelihood of deployment. We used Wyoming brines as examples for the reasons this reviewer mentions. 